\title{
Technology and Innovation Management in Higher Education-Cases from Latin America and Europe
}

\author{
Antonio Adrián Arciénaga Morales ${ }^{1, *}$, Janni Nielsen ${ }^{2}$, Hernán Alberto Bacarini ${ }^{3}$, \\ Silvia Irene Martinelli ${ }^{3}$, Sergio Takeo Kofuji ${ }^{4}$ and Juan Francisco García Díaz ${ }^{3}$ (i) \\ 1 Faculty of Engineering, National University of Salta, Salta 4400, Argentina \\ 2 Department of Digitalization, Copenhagen Business School, 2000 Frederiksberg, Denmark; jn.digi@cbs.dk \\ 3 Department of Social Science, National University of Luján, Luján 6700, Argentina; \\ hbacarini@gmail.com (H.A.B.); martinelliirene@gmail.com (S.I.M.); garciadiazjf@gmail.com (J.F.G.D.) \\ 4 Faculty of Engineering, University of São Paulo, São Paulo 01000, Brazil; kofuji@usp.br \\ * Correspondence: aarcienaga@unsa.edu.ar
}

Received: 5 January 2018; Accepted: 4 April 2018; Published: 8 April 2018

\begin{abstract}
To solve common bottlenecks in the innovation and development process known as the "European Paradox" or the "Latin American Innovative Gap", we introduce different experiences of training and education at graduate level. The main objective of this study is to analyze different cases from Europe and Latin America to synthetize a model of technology and innovation management. Conceptually, the model focuses on competences, tools, skills and behaviors. From this knowledge base, we derive a new model of learning for higher education, using an organizational framework. Our model of learning includes different ways to obtain a panoply of competencies to identify technology and innovation management issues at individual business and regional level, particularly for small-and-medium-sized enterprises (SMEs). The model addresses innovation challenges related to new innovative relationships and product opportunities emerging from traditional sectors, but also from nanotechnology, biotech and ICT fields, with particular emphasis on environmental and sustainability problems. We suggest that our two models may serve as the foundation for designing a curricular master's program for higher education, in accordance with the Latin American and European realities.
\end{abstract}

Keywords: innovation management tools; innovation capabilities; technological innovation; university-company interaction; learning model; higher education

\section{Introduction}

As Schumpeter $(1939$, p. 84) pointed out many years ago, innovation is the main determinant of the dynamics of capitalism's evolution. It is central for a development strategy where innovation is combined with local dynamic entrepreneurship, knowledge generation, competence building, technology transfer and intelligent region policies. Nevertheless, despite the effort of developed and developing countries to promote innovation, there is still a specific gap between academic research and its transformation into valuable products, tools, and resources for citizens and society. In the USA, this gap has been named the "Valley of Death" (Wessner 2008). In Europe (EU), it is called the European Paradox (European Commission 1995, p. 5), which is the perceived and measured failure of European countries to translate scientific advances into marketable innovations (Andreasen et al. 1995, p. 10; Dosi et al. 2006).

In Latin America (LA), it is usually categorized as "falling behind in terms of innovativeness" (Arocena and Sutz 2010). Scientific sources have little or no impact on enterprises' innovation efforts, illustrating the weak liaisons between scientific efforts and national innovation systems in 
these countries (Crespi and Zuniga 2012; Arocena and Sutz 2010; Bravo-Ortega and García 2007). This phenomenon is also frequently a topic of discussions in other regions and countries, such as Australia. Therefore, many stakeholders in different locations have carried out a variety of actions to tackle the many frontlines that delimit this gap. The gap results from knowledge generation not being transformed at a suitable rate into value-added products, services, procedures, methodologies and ultimately, better standards of life for citizens (Andreasen et al. 1995, pp. 10-12).

In Latin American countries with lower scientific capacities, the valley of death is also closely related to a lack of suitable liaisons between academia and productive and social activities. Public interventions have been undertaken to cope with these problems, particularly in Brazil, Argentina, Mexico, Uruguay, Peru, and Chile, demonstrating the current day preoccupation with this issue. All these countries have increased substantially their research activities, and focus on building capacities and competences at country level.

The European Paradox is addressed by prioritizing research and innovation in the Europe 2020 Strategy and the Juncker Commission's 10 priorities (http:/ / publications.europa.eu/web / priorities). Research and Innovation are understood as the key agents of change for Europe, boosting job creation, innovating businesses and education, leading to growth and investment.

Some other problems in the European Paradox or the "Innovative Gap" are the lack of management of specific information and knowledge, particularly among potential investors for uncommon or radical innovative ideas. Good ideas that are inconsistent with or not adapted to the patterns of conventional financiers or marketers tend to be discarded. In this regard, small, innovative businesses face major hurdles, which in turn limit their capacity as key players in bringing new technologies to markets and society (Mäkimattila et al. 2015; Bigliardi and Galati 2016; Van Gils and Rutjes 2017).

There is also a herding tendency that reinforces known technologies against new ones, including venture capital investments. In this sense, there are limited and declining investments in the seed stage of investment, which are also influenced by a lack of proper information (White and Bruton 2011). In the long term, new technologies and new firms shape the structure of markets and societies (including welfare enhancing technologies).

This brief diagnosis sets the border and the name of the problem. In the next paragraphs, we review some explanatory factors and different solutions suggested or implemented. Our critical point of view for the literature review is the scarce analysis of technology and innovation management considered from both organizational learning and educational perspectives, and more specifically the role of organizational learning in connection with university support.

In both regions (EU and LA), there are key common explanatory factors such as imperfect relationships and unsuitable links among universities, business, non-governmental organizations (NGOs), research centers, national and local governments, and other socioeconomic actors. Cooperation between universities and enterprises requires the development of an appropriate structure of relationships and procedures that should take into account both university interests and particularly those of the firms (Debackere and Veugelers 2005). In turn, the origin of this inability to establish proper liaisons is a lack of competencies in collaboration between all the stakeholders, which is necessary for successful innovation processes. Usually, however, policies are focused on infrastructural and science bottlenecks, they seldom take into account this "soft" pre-requisite for innovation.

To address this lack, multiple factors, instruments, policies, and socio-economic innovative requirements were considered. Currently, many research lines cover the majority of these related issues (Sutz 2000; Arocena and Sutz 2010; Bravo-Ortega and García 2007; Crespi and Zuniga 2012; Santos Silva et al. 2013; Martín-Rubio and Andina 2016). However, the educational contributions, especially at university level, necessary for succeeding in coping with all types of complex innovation processes are very limited (in terms of scope) in developed countries (Maassen and Olsen 2007) and even more scarce in developing ones.

In the following paragraphs, we describe a case study analysis, which uses cases from Europe and Latin America. As a complementary source, we include some cases from the literature review and 
our own experience. The cases were the basis for the design of a proposal for the European Program Erasmus+. The submitted project was selected for financing.

The purpose of the article is to understand the focus and scope of a suitable practice for the management of technology and innovation, interpreted as an important tool for solving the innovation gap, and capable of coping with limitations (i.e., uncertainty and complexity) in previous educational schemes. We derive an organizational learning model connected with this approach, which, in our opinion, is the missing link that interrelates the technology and innovation management field with curricular design in higher education. Learning is the crucial base for solving the aforementioned gap and innovation management limitations, whose solutions are of great significance for both Europe and Latin America as well as for other regions.

Having characterized the approaches and solutions adopted in different cases, we develop a model for the management of technology and innovation. The model includes the identification of suitable competencies, behaviors, and tools in the field of technology and innovation management, and their integration into a coherent model. The transformation of such a model into a learning model is the center of analysis in the next focal point of this work (the rationale and methodology are explained in Section 3.1).

Therefore, based on case studies, literature information, and our own experience, we design an alternative model of learning in technology and innovation management. It is worth mentioning that there is abundant empirical evidence that organizational learning and innovation contribute to business performance, and, in turn, organizational learning positively affects innovation (Jiménez-Jiménez and Sanz-Valle 2011). Some of the main characteristics of this model include its cooperative innovation pattern related to circular economies and sustainability (i.e., concepts, business models, and instruments), an education-action approach, e-services and simulation for supporting learning, and new practices of learning, associated with innovation practices in Higher Education.

The development of this paper is as follow: in Section 2, we carry out a literature review with the aim of identifying the different previous approaches in technology and innovation management. In Section 3, we detail the materials and methods used, describing the cases used as source of information. In Section 4, we explain the results that emerge from the analysis of the case studies researched in EU and LA and the literature review consisting in two models, highlighting in turn our findings. In Section 5, we discuss the assumptions, rationales, and guidelines extracted from the case studies considered from both regions, following a case study methodology. This discussion is then applied to both the model of technology and innovation management and the learning model at the organizational level. Finally, in Section 6, we draw some conclusions based on the previous topics, indicating the limitations of the presented research, and taking into concerns educational implication from the technology and innovation management field.

\section{Literature Review}

Links between industry and science are explained to a great extent by "effective" university-based technology transfer mechanisms. Some patterns are critical, such as decentralized organizational mechanisms, incentives to stimulate the active involvement of research groups, methods for exploiting research results, university connections with a well-defined business-oriented cross-section ecosystem, and considering different organizations with diverse roles in the relationships that firms maintain with universities in a regional innovation system. Specialized central services for intellectual property management and spin-off support are also important (Debackere and Veugelers 2005; Friedman and Silberman 2003; Anderson et al. 2007; Striukova and Rayna 2015; Fernández-Esquinas et al. 2016; Hayter and Feeney 2016; Galati et al. 2017). However, the role of education and learning are usually under considered in these analyses.

Besides research results, universities can contribute to solving the gap by creating courses addressing innovation challenges and competencies as well as training capabilities needed. The vast majority of such competencies, which specifically focus on different aspects of the innovation process, 
may be addressed from within the field of technology and innovation management. Despite the many differences between central and peripheral countries, learning needs and skill demands in the field of technology and innovation management are very similar. In addition to the innovation gap, both regions suffer from the same problem of limited current knowledge on technology and innovation management. Tidd (2001, p. 169) description of the problem, which still seems valid today, states: "Several decades of research into innovation management have failed to provide clear and consistent findings or coherent advice to managers." The main limitations for management come from uncertainty and complexity that impact organizational structures and management processes for innovation in different ways (Tidd 2001; Shane 2008; White and Bruton 2011).

In Latin America, there is an awareness of the valley of death, which may explain many educational initiatives promoted by the Inter-American Development Bank, World Bank, and national authorities in specific regions even though the educational initiatives only partially cover some competencies for innovating in different fields. However, whether prioritizing research and innovation in a strategy or promoting educational activities, the essential problems are not addressed. They are the needs for collaborative innovations across sectors and disciplines, as well as the systemic competencies needed for accomplishing it, within a framework of complexity and uncertainty. Some successful universities manage contacts with different financial sources, have experiential understanding of firms' strategies, and can support the idea generation process for future enterprises' plans (Veugelers and Cassiman 2005). To great extent his success is based on an implicit or explicit comprehension of organizational learning processes that are happening within the productive tissue.

Some border conditions closely related to internal and external learning are lost in many approaches usually carried out by universities in Latin America when attempting to understand innovation management and technology transfer. Some of the most important unconsidered conditions are the following (Santos Silva et al. 2013, p. 78):

- The uniqueness of each academic organization or research center.

- The regional context in which liaisons actions are deployed.

- The characteristics of the firms in relation to the innovation process.

- Information technology is crucial for management efficiency. However, it encourages but cannot deliver knowledge management and learning within organizations (McDermott 1998).

- The internal relationship between academic research agenda and entrepreneurial innovation.

- The correlation and co-evolution between the organizational development and the innovation process in the manufacturing and academic areas.

Another important missing link in the innovation gap solution is the model of learning for effective practices and tool design in the management of technology and innovation. A learning model at organizational level is very important to solve dynamically—at least partially at the beginning-one's own limitations of higher education in the innovation field. How is innovation being conservative or resilient to change taught? How is technology management being refractive or contrary to implementing technological solutions such as blended learning taught? Thus, learning models are crucial for a suitable curricular design and teaching of these management topics, particularly at the university level.

In the learning field, there are three inquires or issues to highlight. First, while all the studies provide adequate focus on $R \& D$, technology management, innovation process, technology transfer, and even training general competencies, they often fall short in terms of understanding specific competencies and tools that address the context factors, e.g., uncertainty, complexity, globalization, and rate of learning. These factors deeply affect the capacity to manage complex fields such as technology and innovation management. Second, and as necessary conditions given the evolving nature of technology and innovation management, the main research question is what architecture of concepts, competencies, strategies and tools ensure firms and society the capacity to transform any type of knowledge into value-added outcomes for everyone. Furthermore, the link between decision processes under conditions of uncertainty and abilities (cognitive competencies and skills) is largely 
uninvestigated (Cokely and Kelley 2009, p. 20). Third, connected to and derived from both these issues, another important aspect is what "avenues" converge with solving the learning challenges of such an architecture and decision process with contributions from the academic field, particularly educational solutions. For the innovation bottleneck framework posed for both regions (EU and LA), these three inquiries are relevant to understanding how to teach collaborative innovation, how to manage risk and uncertainty, how to convert entrepreneurial ideas into innovation, how to develop systemic competencies, and how to evolve knowledge and practices of teaching and learning for a dynamic complex subject. The changing nature of open and collaborative innovation (Horn 2005) in the Internet era seems to be the Achilles heel of the majority of previous academic schemes focused on technology and innovation management. Moreover, previous research on this topic also seems to show a gap with less explored issues in answering the interconnection in the above-mentioned inquiries (see Section 5.1), which are theoretical and instrumental ones. This article will attempt to add some new knowledge in this sense.

The nature of the management of technology and innovation as a study field is not strictly a technical domain or a business discipline, but both. As an applied rather than a theoretical discipline, the associated knowledge requires realistic settings to ensure suitable learning. This knowledge area requires an integrated approach for both scholars and managers. The integrated approach also means that all the competencies, tools, procedures, and knowledge related to this field are deeply intertwined among them (White and Bruton 2011; p. xv).

Many authors have tried to classify and order the different competencies and tools included in technology and innovation management. Certainly, the criteria and assumptions are inherently important for that task. For example, an organization's size matters because management techniques are different in SMEs compared to large firms (Eveleens 2010, p. 4) even though some tools can be adapted for different firm sizes, management styles, and focuses on innovation.

Table 1. Approaches to Technology and Innovation Management. Source: Own elaboration.

\begin{tabular}{|c|c|c|}
\hline Authors & Original Proposal & Shared Tools and Competencies \\
\hline Dogson (2000) & $\begin{array}{ll}\text { - } & \text { New Product Development } \\
\text { - } & \text { R\&D management } \\
\text { - } & \text { Commology Strategy } \\
\text { - } & \text { Technological Collaboration } \\
\text { - } & \text { Operations/Production } \\
\text { - } & \text { Organizational Learning } \\
\text { - } & \text { Creativity } \\
\text { - } & \text { Complexity } \\
\text { - } & \text { Risks }\end{array}$ & \multirow{3}{*}{$\begin{array}{l}\text { - } \quad \text { New Product Development. } \\
\text { - } \quad \text { Technology and Innovation Strategy. } \\
\text { - } \quad \text { R\&D management. } \\
\text { - Project Management. }\end{array}$} \\
\hline Shane (2008) & $\begin{array}{l}\text { - } \quad \text { Development and Introduction of New Products. } \\
\text { - } \quad \text { Management and Organization of Innovation. } \\
\text { - } \quad \text { Portfolio Management. } \\
\text { - } \quad \text { Technology and Innovation Strategy. } \\
\text { - } \quad \text { Intellectual Property and Innovation. } \\
\text { - } \quad \text { Technology-Based Entrepreneurship. } \\
\text { - } \quad \text { Financing of Innovation. }\end{array}$ & \\
\hline Adams et al. (2006) & $\begin{array}{ll}\text { - } & \text { Management of inputs. } \\
\text { - } & \text { Knowledge Management. } \\
\text { - } & \text { Innovation strategy. } \\
\text { - } & \text { Organizational culture and structure. } \\
\text { - } & \text { Project management. } \\
\text { - } & \text { Commercialization }\end{array}$ & \\
\hline
\end{tabular}


Table 1. Cont.

\begin{tabular}{|c|c|c|}
\hline Authors & Original Proposal & Shared Tools and Competencies \\
\hline Tidd et al. (2005) & $\begin{array}{ll}\text { - } & \text { Strategic Approach. } \\
\text { - } & \text { Strategic Learning. } \\
\text { - } & \text { Setting Effective External Linkages. } \\
\text { - } \quad \text { Creating Innornal Process. } \\
\text { Creative New Firms. }\end{array}$ & \\
\hline Lopes et al. (2012) & $\begin{array}{ll}\text { - } & \text { Organizational Strategy } \\
\text { - } & \text { Project Management } \\
\text { - } & \text { Knowledge Management } \\
\text { - } & \text { Types of Innovation } \\
\text { - } & \text { Technological Innovation } \\
\text { - } & \text { Open Innovation. }\end{array}$ & \\
\hline
\end{tabular}

The literature review reveals a field of study characterized by a diversity of approaches, prescriptions, and practices; some of which are confusing or even contradictory. According to this specific literature, the territory of technology and innovation management is vast and spread across several disciplines. Given such diversity, there is not an integrated approach or a holistic framework that currently covers the whole range of investigations in technology and innovation management. There are many theoretical lines of research, but they evolve in relative isolation, with scarce relationships and integration, making it very difficult to see the whole picture (see Adams et al. 2006; Van de Ven et al. 2000; Poole and Van de Ven 2004, p. vi; Eveleens 2010).

Our approach to reviewing the literature was attempting to integrate the different competencies, tools, and behaviors involved in this field. We identified leading scholars who proposed different tools, skills, and activities to define the limits and contents of technology and innovation management. Table 1 summarizes the different proposals and the shared points.

An alternative approach is to define technology and innovation management in terms of the disciplines that influence this specific area of management (White and Bruton 2011, p. 16). We define the competencies, behaviors, and tools involved in the deployment of activities related to technology and innovation management. We propose this central approach for defining the model, as described in Section 4.1. It connects better with an advanced learning perspective and further educational purposes.

It can be pointed out that the rationale behind all the classifications (Table 1) is that, within technology and innovation management, there exists a central chain of competencies and tools, which, in turn, are closely related to the logical or heuristic sequence of the decision-making process:

- Gathering of information: prospective, technology surveillance, and competitive intelligence (these tools and skills are not explicitly present in Table 1 but they are included in the case studies; see Section 3.2).

- Diagnosis of the problems or opportunities: problem solving, organizational culture and structure, organizational learning, and complexity.

- Strategic solution with problems or opportunities as goals to achieve: technology and innovation strategy, setting effective external linkages, technological collaboration, new product development, strategic learning, creating innovative new firms, and open innovation.

- Concrete actions to obtain such solutions: new product development, R\&D management, commercialization (including introduction of new products), intellectual property protection, technology-based entrepreneurship, input management, knowledge management, project management, managing internal process, product management, and technological innovation.

- Financing all the above activities: financing of innovation.

Additionally, decision-making in uncertain and risky environments is typical of complex, multi-variable, unstructured, systemic, and unplanned problems or situations, which is similar to decision-making related to technology and innovation management (Rutherford-Silvers 2008). 
From this last viewpoint, decision problems involve processing and transforming such information and understanding into useful knowledge to manage technologies and the innovation process: product development, design, production and its organization, strategies, problem-solving, financing, planning, and marketing of new products.

However, as we already mentioned, the link between decision processes and abilities (i.e., cognitive competences and skills) is largely uninvestigated (Cokely and Kelley 2009, p. 20). The relationship between cognitive abilities and superior decision-making in risky and uncertain situations is not clear regarding the cognitive processes that give rise to this link. Along the decision making process, it is important to emphasize the relational character among the different stages of the decision process and the importance of these relationships for understanding technology and innovation management. Nevertheless, such stages are not a linear sequence of steps but a chain with cross-fertilized connections, following interactive models of innovation and complex decision-making heuristics or models.

Applying management decisions in organizations has brought new dimensions in technology and innovation management theory (Wollmann and Steiner 2017; Annavarapu 2016; Liew and Sundaram 2005). In the technology and innovation management field, complex decision-making models can be thought of as a circular chain with the main following links (cf. Arciénaga 1995):

- Awareness competencies and tools provide information for and advice to organizations. These involve not only the search and provision of information but also tools, which aim to make entrepreneurs aware of their needs for information. The awareness competencies ensure the whole panorama of sources define and solve, in a suitable way, the firm's need for information and knowledge related to the decision-making process within the company.

- Auditing or diagnostic competencies and tools help the organization to detect and focus on actual problematic issues or available opportunities. Here, issues are those about which enterprises need to make a decision. Therefore, auditing has a wide range of elements with which to deal. These types of abilities are connected with the enhancement of the "organizational intelligence process", because they provide knowledge of the organization's relative position and possibilities for change. They are also critical for dealing with complex problems in situations of uncertainty, connecting fact-finding with defining problems or opportunities in a progressive manner.

- Competencies and tools to develop a strategy allow the identification of options, priorities, and goals for actions. These are also concerned with upgrading the "organizational intelligence process", providing knowledge of where the firm needs or wants to go. More specifically, this addresses the changes and questions required to achieve future objectives.

- Competencies and tools for taking actions are fundamental to assist the organization in determining what it needs to do and how it should carry out the desired changes. As actionrelated activities, they improve the organizational learning process. One critical competence and tool here is project management. Another is problem solving for organizational learning.

- Additionally, the financing competencies and tools for technological and innovation projects is another important part of this puzzle of technology and innovation management, especially for SMEs, for closing the circle of competencies, attitudes, aptitudes, skills, and tools necessary.

More details and discussions based on this literature review are explore in Sections 4 and 5 together with data from case studies, described in Section 3.

\section{Materials and Methods}

In this section, we describe the methodology of case studies adopted, and the rationale and sequence of the study carried out. Following this we present the details of the cases which are the main sources of information and experience. These cases are the basis for the induction process that concludes with the building of the models proposed. 


\subsection{Rationale and Methods Used}

The main objective for this work-specified in the EU funded EULA-GTEC Erasmus project description-is the design of a curricular master's program for higher education, in accordance with the Latin American and European realities. The starting point of this study was the analysis of different cases, in both Europe and Latin America. Some cases in North America were also reviewed, as was data from relevant published studies. On this basis, we formulated a model of technology management. This model was focused conceptually on competencies, tools, skills, and behaviors. Next, we derived a learning model based on the organizational framework. All these components were the foundation for designing a future curricular master's program for higher education. Figure 1 is a representation of the approach we adopted. It shows what we did, in which sequence, the essential concepts and how the components overlap. The arrows show the direction of reasoning, from the starting point of cases, literature and our own experience, and the resulting models from case studies to learning model.

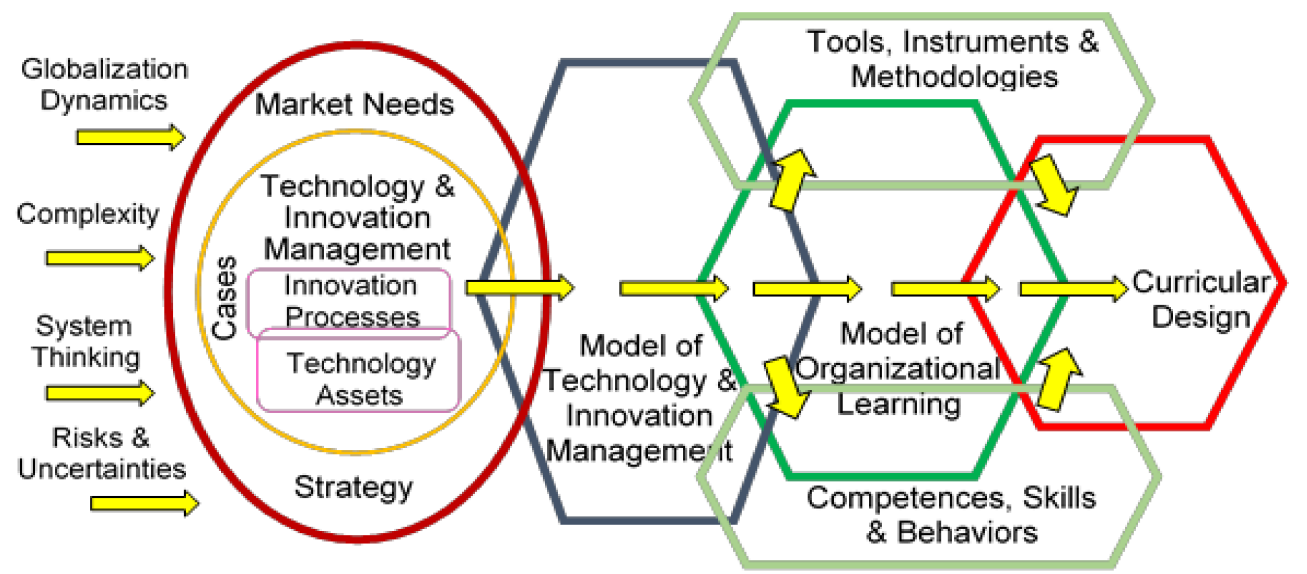

Figure 1. Approaches of the Study. Source: own elaboration.

The case study methodology consisted of describing an interesting number of experiences in the field of technology management teaching and researching in higher education, covering both regions (Europe and Latin America). First, we derived from them some stylized facts shared by the cases. The concept of stylized facts is based on the methodological proposal of Kaldor (1961, p. 179) for the social sciences. The first step was to characterize a complex surveyed subject by identifying the main topics, issues, or facts of the cases observed. Next, these facts were grouped according to similar characteristics, which also developed from observation. Then, these emerging categories of classification were inductively connected to introduce a dynamic focus on the subject. Finally, through following these steps the model unfolded (Figure 1).

Thus, case-based studies rely on the concept of similarity, and more particularly on the idea that situations, issues, or facts being recognized as similar in important aspects may also be similar in other respects (Hüllermeier 2007, p. 5). Therefore, our approach was based on a simple instance of analogical or inductive reasoning that would result in a general model for technology and innovation management, and a model of organizational learning.

All these described steps highlight the nature of a case study as a theory-building search rather than theory-testing research (Eisenhardt and Graebner 2007, p. 26). Analyzing multiple cases, such as in our situation, often emphasizes complementary aspects of a phenomenon. Furthermore, it allows three important properties: replication, corroboration, and extension. Replication means that individual cases can be used for independently corroborate specific propositions. In turn, corroboration is the process that allows researchers to more easily perceive patterns, eliminating chance associations. Finally, extension refers to the possibility of inducing a more developed theory, 
model or the explanation based on multiple cases. Putting all the parts of the puzzle together allows the researcher to draw a more complete theoretical picture or model (Eisenhard 1991, p. 620).

Recognizing patterns of relationships among constructs within and across cases is a crucial task for creating a model. Case studies are different from lab experiments in the sense that they emphasize the rich, real-world context in which the phenomena occur. Theory-building is an emerging process that is based on recursive cycling and integrating the case data, the theoretical creation of constructs or models, posing propositions and midrange theory from cases; all these are based on the empirical evidence (Eisenhardt and Graebner 2007, p. 26).

Complementary to the analysis carried out above, we added an abductive approach to case studies. The merging process of mixing empirical fieldwork with case analysis and theoretical framework gives rise to a methodology called systematic combining. This methodology is particularly useful for developing of new theories in the management field. For such purpose, two epistemological processes were involved: matching theory with reality and dealing with direction and redirection of the research according to the theoretical framework (Dubois and Gadde 2002, p. 553).

\subsection{Materials}

The materials for this work are essentially the cases reviewed in Europe and Latin America. In the following paragraphs, we describe and synthesize the different cases under analysis. First, we introduce the cases that were surveyed directly by the partners of the EULA-GTEC Erasmus project. Then, we include some leading cases taken from the literature. The descriptions in both cases try to highlight stylized facts and patterns that arise from these sources of information.

While these summaries cannot do justice to the richness of each initiative, they show at least the significant effort involved and the edges or facets of interest. The main patterns or facets studied in each case are the general framework of the experience, objectives, description of the initiative, competencies and profiles of the students, and the results.

Next, there is a summary description of each case, following the structure mentioned $i$ above. Partners of the EULA-GTEC project provided most of the information for each case, except the last two, with information from the literature and the Internet.

The following is a brief synopsis of each case:

1. Master's Program of Engineering of Innovation-University of Bologna (UniBo): This is a private Italo-Argentinean experience focused on training managers in the introduction of innovation and the mastery of most advanced technologies. From 2001 to 2010, UniBo proposed and executed six editions of the master's degree, organized in Buenos Aires and Bologna. The UniBo master program's target audience were graduates from engineering, economics and management careers. The degree involved a cultural and training experience in both Europe and Latin America. The curriculum was structured in 16 modules; 8 were technology-based and 8 economics- and management-based. Each module included 80 hours of coursework during a 4-week period. Practical activities and workshops occupied half of each module. Thirty graduates were awarded with the master's degree. All of them are working in important positions in both public and private organizations.

2. Argentine National Program for Training Technological Managers and Brokers (GTec): It is a national public initiative launched in 2010 that until now-in practice-gave continuity to the above program, while embracing the whole country. The main participating partners are public and private Argentinian higher education institutions. Other agents such as industrial and commercial chambers or regional development authorities can also participate in the initiative. GTec's focus is the professional training of managers and other key actors to promote innovation and technology transfer within the country. The GTec students are innovative entrepreneurs, consultants, engineers, professionals, developers, local officials, industrial chambers' managers, personnel from academic offices of technology transfer, technology and business brokers, and researchers who specialize in the productive development through innovation processes. 
This new profile should be able to detect innovation demands, facilitate the creation or articulation of technological opportunities, promote entrepreneurial innovation, and translate academic R\&D into solutions for the productive sector. More than nine hundred students have been trained in this graduated educational scheme until now. Many follow-up initiatives are in place to support the consortia, particularly in curricular design and scholarships in foreign technology transfer offices and promoting the acceptance of this new professional profile in the job market.

3. Initiatives of the University of São Paulo (USP, Brazil): This is the oldest experience in LA. The Node of Policy and Technology Management (PGT) focuses on technology and innovation management both as a research line and as a training field. Training of competencies is closely related to applied research. In parallel, USP established the Agency of Innovation in 2004, where USP researchers perform theoretical and practical reflection on the role and ways a university, facing its limitations and opportunities, can carry out innovation both internally and through cooperating with the surrounding productive sector and society. It also offers support for teachers, students, and USP staff in developing projects in partnership with the business sectors as well as to communicate and disseminate to society the impact and benefits of innovation guided by science (developed by researchers from USP). According to academic production (e.g., articles, $\mathrm{PhD}$ and master's thesis already produced; see http:/ / pgt.prp.usp.br/ artigos/), PGT is an important platform to qualify human resources in technology and innovation management. Therefore, results are largely qualitative. Other USP initiatives related to technology and innovation management are the business incubators. Particularly, the FIWARE Lab is an open platform whose goal is to disseminate innovation through startups. The basic contribution of FIWARE Lab to innovative projects is to assess conceptual and application testingof projects for possible uses. It promotes events such as lectures and workshops in collaboration with universities, companies and governmental institutions, aiming to promote the platform within smart city context. Since 2013, the Polytechnic School of the University of São Paulo within the department of production engineering promotes massive open online courses (MOOCs) in partnership with VEDUCA for Latin America. The School also promotes several courses on the CORSERA platform, providing free universal access to better education with online courses, particularly in the field of technology and innovation management. This and other USP initiatives exert a great influence on the technology and innovation management field in many LA countries and are probably the most advance strategy in LA for this purpose.

4. Other Brazilian Experiences: The Professional Graduate Program on Intellectual Property and Technology Transfer for Innovation (PROFNIT) is a recent national initiative very similar to GTec in Argentina, which emphasizes technology transfer. Courses integrate a master's degree; its objective is to train human capital for the nodes of technological innovation (NITs). The national innovation law (Law $\mathrm{N}^{\circ} 10.973$ of 2004) established NITs as the promoters of local innovation initiatives, involving different stakeholders (e.g., academy, business, governmental officials, and social organizations). Launched in 2014, PROFNIT has been training personnel since 2016. PROFNIT is integrated as a national network with 12 focal points around Brazil. All these points are universities. Currently, there are 430 NITs distributed throughout Brazil and affiliated with FORTEC. This institution is constituted as a civil Brazilian association for innovation and technology transfer managers (see www.fortec.org.br). The master's graduates are essentially prepared with suitable competences to play a role within the NITs. Thus, they must have skills for promoting academic-business dialogue interacting creatively with the governmental, business, and academic sectors. PROFNIT post-graduate program effectively began on 2016. It included 101 students from all over Brazil. They finished on December of 2017; therefore, there are not graduates yet.

5. Master's Program from Peru: This experience is an answer to the economic growth experienced by the country in recent years, which triggered an increasing demand for R\&D and innovation in the manufacturing sector as well as in the national boards and organizations devoted to 
R\&D and regional promotion. The program includes concepts, tools, methodologies, and a hands-on approach to ensure that the main issues around the innovation process are considered. The master's experience is intended to incorporate success cases and best practices of innovation to generate a relevant and suitable impact on institutional and managerial routines. In parallel, the master's degree provide training in competencies to specialists interested in the design and application of policies in science and technology public organizations. In both cases, the acquired capacities and skills will facilitate the management of research, development, and innovation in public or private organizations at different levels of complexity. The master's plan embraces 10 obligatory courses, 3 electives, and 2 seminars for the thesis. The courses involve 4 semesters of duration. At the end of the first year, there is an intermediary diploma on technology and innovation management. The master's program has many institutional supports. It receives scholarships from the national Fund for Innovation, Science and Technology (FINCyT). Furthermore, PUCS has an agreement with USP and the PGT in the academic field. The Latin-Iberian American Association for Technology Management (ALTEC) has backed this master's program. ALTEC gathers the most qualified scholars and practitioners in the field of technology and innovation management in Latin America and the Iberian Peninsula. Additionally, the master belongs to the MIT Global Supply Chain and Logistics Excellence (SCALE), of the Massachusetts Institute of Technology's engineering school. Students interested in logistics innovation have the option to complete some courses and obtain the MIT Graduate Certificate in Logistics and Supply Chain Management (GCLOG). Since the master's program was launched in 2010, 49 students have graduated. Their theses also promote innovation management in Peru.

6. Minnesota Technology Management Program (MTMP): This experience was included to understand a historical and pioneering proposal in the field of technology and innovation management. This program began in 1983 with the objective of developing a process theory of innovation in organizations and society. Thus, MTMP pioneered studies and modern concepts in the field of technology and innovation management. The program involved fourteen research teams and more than 30 faculty and doctoral students at the University of Minnesota who conducted longitudinal studies that tracked a variety of new technologies, products, services, and projects as they developed from concept to implementation in their natural field settings (Schroeder et al. 1986). The main objective of MTMP was to understand how innovations actually develop over time and to determine what factors influence the successful development of these innovations (Van de Ven 1986, p. 1), particularly in the management field. One of the main questions in this research was about what forms of organization and management facilitate and inhibit innovations over time. In searching for an answer, researchers compared different organizational settings for innovation (e.g., new business startups, corporate sponsorship of new businesses, inter-organizational ventures, mergers and acquisitions, and internal corporate entrepreneurship) (Van de Ven 1986, p. 2). Methodologies for researching innovation management are the main competencies and tools generated as contributions of the MTMP program. In this sense, tracking historical and real-time events in the development of an innovation process, is key to understanding how innovations emerged and developed over time (Poole and Van de Ven 2004, p. vi; Schroeder et al. 1986). MTMP's published findings influenced the next generation of studies and research in the field of technology and innovation management. This program also brought order to the extensive range of theory and research they synthesized. Finally, the methods and tools for studying innovation management and organizational change they discovered are available now in several publications such as Poole et al. (2000), Poole and Van de Ven (2004), Van de Ven and Poole (1990), and Van de Ven et al. (2000).

7. Master in Research and Innovation in Higher Education (MARIHE) Joint Master's Degree: This is an Erasmus+ European experience characterized by generating graduates with capabilities for academic innovation management. This is another approach in solving the innovation gap. The MARIHE program (see http://www.marihe.eu/) is appropriate for students who wish 
to pursue a career in the higher education and research sector as managers, administrators, consultants, policy analysts, researchers, and decision makers. This is another side (blurrier or less direct in our opinion) of technology and innovation management. Possible employment include higher education and research institutions, public bodies such as ministries for science and education, enterprises specializing in education, think tanks, and non-governmental organizations. The master's degree program is oriented to enhancing the higher education system as the main strategy to improve the knowledge triangle (i.e., industry, academy and government). There are important differences between this knowledge triangle and the Sabato's triangle, with dissimilar meanings for edges, which result in different strategies to promote innovation. Sábato and Botana (1968) triangle model is at the base (though not recognized), of the triple helix model. Three perspectives are at the foundation of MARIHE's curriculum design. These perspectives reflect the effects of global changes on system transitions (due to globalization and regionalization), new systemic interactions (system-institution interaction, e.g., funding research and innovation), and the difficulties of institutional changes (e.g., management in HEIs). The rationale behind these perspectives is that such changes are now a worldwide framework, which significantly influences higher education design and the management of higher education institutions. Danube University Krems (DUK), located near Vienna, is the MARIHE program's coordinating institution. Graduates of MARIHE are awarded a joint degree. Students spend the fourth semester with courses at partners such as the University of Tampere, Danube University Krems, or Beijing Normal University. During the fourth semester, students must choose between two alternatives. The first is for students wanting to specialize in the field of research and innovation management in HEIs. The second alternative is for students to choose the research and analysis of research and innovation in HEIs. The program has a graduation success rate of over $90 \%$. Since its launching in 2012, 59 students have graduated. In addition to the master's thesis, each student writes a special summary of the thesis, which is an extract. This extended summary is published as an e-book in a collection of summarized master's theses freely accessible through the web.

The first five initiatives had relatively similar curricular design and covered many of the competencies and tools detailed in Sections 2 and 4.1. Most included risk management but did not specifically address uncertainty, system thinking, and complexity. Another weakness was the lack of consideration of innovation based on the servitization process, which is much broader than innovation in the service sector (Beuren et al. 2013, p. 224). Furthermore, cases showed different learning strategies and methods, but they did not cover all the possibilities in terms of the learning process itself, and the learning methods are usually taken separately. Another common edge or facet was sustainability, but training programs only addressed environmental regulations in relation to innovation and lacked any tool or competencies for circular economy approaches and responsible innovation. No training programs were specialized in one sector but provided competencies and tools for technology and innovation management in productive activities in general.

In the Brazilian experiences, the emphasis was more on technology transfer and intellectual property rights than on innovation management, even though some management techniques were included. It is also interesting to note that the professional profile of a chief technology officer (CTO) is uncommon for big firms in LA and almost nonexistent for SMEs. Therefore, in all the five cases, the experiences included some brokering interactions between universities and the job market. Finally, in all cases, there were problems with management tools adapted to SMEs because most were originally designed for big and multinational firms in developed countries.

\section{Results}

This section includes the presentation of two types of results. First, we describe a model for technology and innovation management based on case studies, which involves cases from Europe and Latin America as well as the research literature. Second, another result drawn from the first is defined 
in the next subsection. It is essentially a model of learning in technology and innovation management, established specifically for the organizational level. In both models, we describe their main stylized facts or features, contrasting evidence from the literature with findings from case studies.

The assumptions and rationale at the base of these two models, most of them common for the circular approach chosen, are summarized in the following propositions:

- The majority of the activities and processes embraced in technology and innovation management are exploratory in nature, not repeated procedures. Therefore, there are usually a significant degree of ambiguity and uncertainty in the knowledge, competencies, tools, and behaviors required in each activity and for the learning processes involved.

- Another important fact is the embedded character of many organizational processes and elements, such as decision-making processes, group behaviors, individual skills, heuristics rules, tools, methods, routines, systems, and heterogeneous networks. For being incorporated and finally embedded, these organizational factors should present a dynamic learning process.

- Local or own tacit knowledge is crucial for learning explicit external technology and innovation management good practices (Lall 2000, p. 15). Own ideas are the necessary basis for giving new organizational meanings to new and old knowledge, competencies, values, tools, networks, systems, and behaviors. In this context, ICTs are good for transferring explicit or codified knowledge and know how, but they are very limited to transfer tacit knowledge (e.g., nonverbal information, intuitions, tacit rules and rationales, some heuristic criteria), which is crucial for organizational learning at individual, group, or team level, and even the whole organization.

- Ensuring a dynamic learning process at organizational level, including interactions and co-creations processes with different stakeholders, seems to be a necessary condition for successful mastering or assimilation of new knowledge and technologies (Kim and Nelson 2000, p. 2).

- Combinatorial capabilities can articulate poorly articulated knowledge, which is difficult to learn and diffuse among organizational employee (Machado and Davim 2015, p. 98). Therefore, in technology and innovation management learning, the replication of good practices, recombination of own and external ideas, re-creation of old and new tools, internalization of new behaviors, articulation of old and new methods, appropriation of external models, articulation of networks, and re-utilization of tools and systems, are clearly not a linear process.

- Learning activities are carried out in all forms of organizational arrangements and contexts, including virtual projects and teams. Therefore, there is not a unique organizational context for good practice in technology and innovation management and learning in modern organizations.

Based on these assumptions, we propose a circular model for both technology and innovation management, and for the connected learning process. They will be described and explained in Sections 4.1 and 4.2 Both models share in common the following patterns:

- The dependent variable is located in the central point of the figures (Figures 2 and 3). In the first case (Figure 2), different competencies, tools, and behaviors can explain good practice of technology and innovation management. In the second case (Figure 3), successful learning in this field is explained by a combination of different convergent avenues with different forms of learning.

- The next area around the center of the circle includes all the interdependent variables (i.e., not independent variable), given that we are dealing with complex systems. This means that competencies, tools, and behaviors can be combined among each other to solve complex issues, for dealing with uncertainties, and for learning poorly articulated know how, tools, and behaviors.

- The contexts for technology and innovation management practices and organizational learning are considered here near the external circle in both figures (Figures 2 and 3). They can be conceptualized as latent variables.

These basic assumptions and the suggested models are in line with the main perspective of analysis of this paper, which is to connect technology and innovation management and organizational 
learning with university training actions. Therefore, Section 4.1 details the model for technology and innovation management, and Section 4.2 makes similar task with the model of learning. Finally, in Section 4.3 , we briefly synthetize all the findings of this paper.

\subsection{Model for Technology and Innovation Management}

To model technology and innovation management, we considered external factors influencing this field of management as well as internal determinants and their connections. In the following paragraphs, we describe these factors and the suggested model, highlighting the educational connection in terms of competencies, behaviors, and tools.

To address a diversity of aspects and problems related to overcoming the valley of death, the European Paradox or the innovation gap, we do not conceive the innovation process as linear. Our assumption is that innovation is interactive in nature (Lundvall 1988; Mytelka and Smith 2002), and products, processes, and organizational changes are co-created through a cooperative process of innovation, with the effective participation of diverse stakeholders.

This co-creative approach is fundamental for coping with not only the uncertainty and complexity of the innovation process and the organizations involved but also with the bounded rationales of the stakeholders involved in this process. Co-creation is closely related with co-evolution of the innovation process. For instance, product innovation solutions require a process of co-creation by means of the participation of suppliers and producers, and even advanced final customers, to obtain feasible results. The important positive role of advanced customers for the innovation process was well proven by Erick von Hippel in many publications (for example, Von Hippel 1988, Thomke and Von Hippel 2002). Collaboration and co-creation imply dealing with a new type of customer along the value chain. Old customers are passive consumers of products instead of active collaborators and co-producers of value. They emphasize transaction-based relationships instead of interactions and experience-based relationships. They always prefer to be a fixed and invisible link at one point on a long value chain instead of being an adaptive and very visible link. Finally, for old customers, the concept of value is related to what companies offer (one size fits all) and not the criteria that the customer determines and tailors a unique solution and a customized experience (cf. Bhalla 2011, pp. 4-5). The cooperation or collaboration could be extended even to rival firms (Von Hippel 1987).

The multiple relations among the diversity of stakeholders is open for a co-evolution of the different stakeholders and evolution of the whole process of innovation, also at a regional level. Therefore, intelligent regional actions also involve a system thinking approach to consider and manage all the complexities of the innovation process deployed in a territory. The environment is another important issue for technology and innovation management, especially regulations and a deeper understanding of innovation impacts, in a particular environmental field or a socio-economic area, which usually lead to significant time lags for the development of novel innovations (see details for nanotechnology innovations in Owen and Goldberg 2010). There is an increasing concern for environmental risks in the utilization of new products or processes that includes not only the regulators but also consumers and the industries.

Therefore, responsible innovation is almost a "sine qua none" condition for innovation today and in the near future. Many unintended consequences of human actions, especially those related to global climate change, are modifying the behavior of governments, firms, and society (Owen et al. 2009; Ishizu et al. 2008) because their effects may be so profound that the very future of human society is at great risks. Innovation is not an exception in this forced evolution.

To avoid catastrophic consequences responsibility seems to be the answer to this survival requirement. Therefore, the need to innovate is entering a new phase: to innovate responsibly (cf. Owen et al. 2009, p. 6902). In the Japanese experience, responsible innovation means thinking right from the beginning about societal acceptance of the technology and the innovations based on it (see Ishizu et al. 2008). We should mention that the cases studied have been incorporating a common responsible preoccupation for regulations, reflected particularly in rules related to managing environmental sustainability. However, 
two advanced aspects of sustainability, i.e. circular economies and responsible innovation, were not addressed as tools and competencies in the cases studied or in the literature review.

Otherwise, how can big, medium, and small innovative firms cross the valley of death, in a specific local field of knowledge in an uncertainty and complexity system management? In the linear model, the answers to this question - at the end-arise from the rationale related to the rate of firm investments. However, in the interactive and cooperative rationale, there are many possible answers to this question. They involve taking care of not only risk capital or financial supports but also other internal and external firm's and personnel competencies to overcome a diversity of bottlenecks and issues that directly affect the ability of such firms to innovate. Even governmental and societal regulations and culture influence the possibilities and criteria for handling complex social and environmental issues. Going beyond the identification of all competencies and instruments for solving the European Paradox and the innovation gap embedded in the management of innovation and technology, we can synthesized a model of relationships in a graphical form. In Figure 2, the external circle shows the basic conditions or contexts necessary to manage or apply successful management in technology and innovation. Some of them are external to the organization (e.g., globalization), some internal (e.g., system thinking), and others are both internal and external (e.g., complexity, uncertainty, and risk). The inner circle includes the specific tools and competencies for technology and innovation management. Despite the circular and interrelated character of the main competencies and instruments within this model (Figure 1), it can be observed that the instrumental knowledge competencies and tools for technology and innovation management can be considered as a starting point for the strategic management of technology and innovation. The ending point is an operative competence for problem solving, following the circle in the counter-clock direction. In the middle of both, other competencies and tools include product development, research and development (R\&D) management, technology transfer, and more. In other words, this model of technology and innovation management requires not only that the large picture (of the strategy) is considered but also follow-up on smaller details (problem solving at plant and working space level).

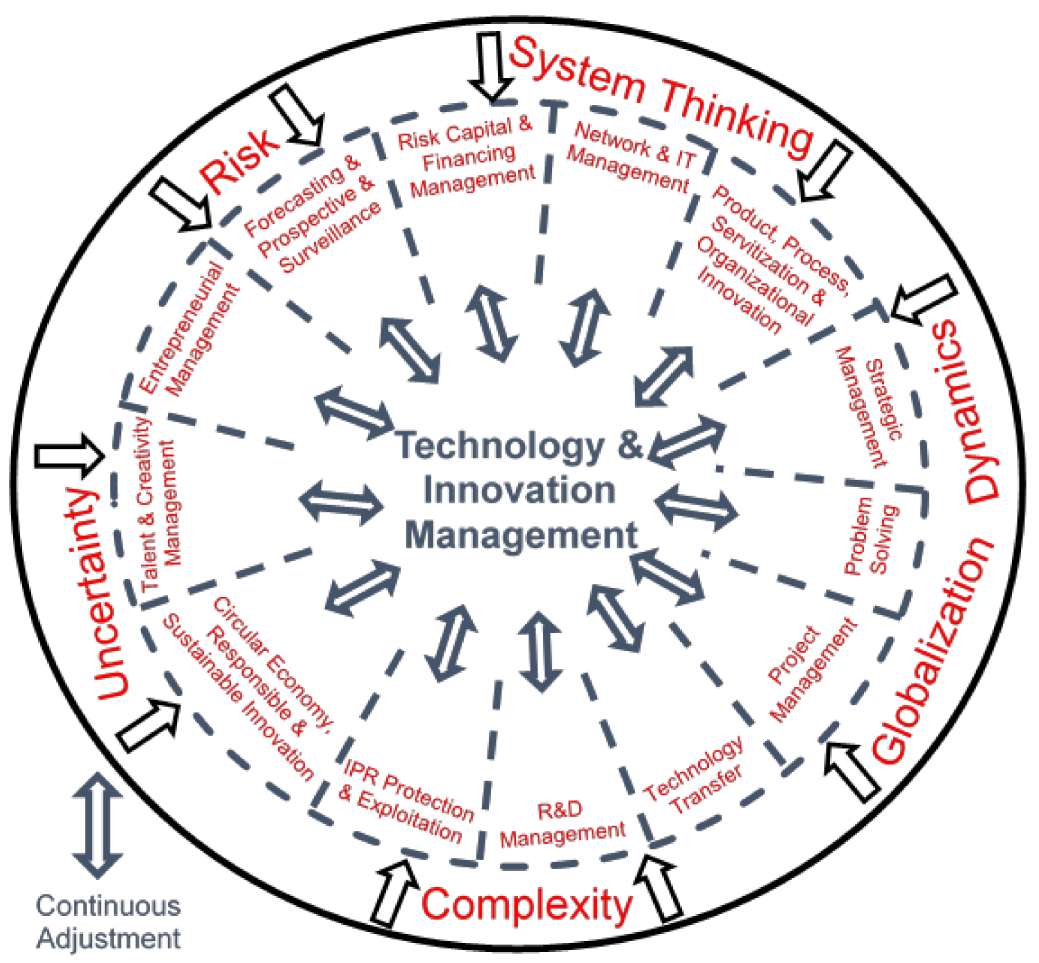

Figure 2. Model for Technology and Innovation Management. Source: own elaboration. 
These competencies (Figure 2) recognize the interdisciplinary nature of technology and innovation management and the participation of many different practitioners, from general to specialized professionals, with an inter-professional and interdisciplinary approach to learning and practice. The competencies and framework described in this paper have relevance for several functions or processes, diverse stakeholders, and priorities for different learning process. This model involves some of the following concepts and characteristics:

- To be most effective, an organization should integrate these competencies identified for technology an innovation management into a core competence (Hamel and Prahalad 1994; Ljungquist 2007). Following this theory, a core competence is an integrated and derived core capability, which in turn explain business performance and corporate growth (Yang 2015).

- Setting all the competencies, tools, and behaviors in a circular integration means that there is no pyramid or hierarchy of competencies, capabilities, resources, or tools as suggested by empirical studies (Ljungquist 2007). This means that all associated concepts (e.g., competence, capability, and resources) have equal weight at the same hierarchy level.

- The critical competencies, behaviors, and tools identified in this model serve as the foundation for gap-closing strategies at the organizational level based on organizational learning.

- These competencies are also useful for other processes, including employee selection, performance management, professional development, and curricular design and training.

- Competencies can be adapted to existing resources according to their quality and availability for a firm (following the theory of resource-based firm). In turn, dynamic capabilities can renew existing resources and tools (Peteraf and Bergen 2003).

- The definition of successful performance will very likely vary with each organization's mission, vision, and values. Therefore, specific competencies associated with superior performance may also differ from one organizational culture to another. Despite this, organizations wishing to make a significant change in their strategic innovative behavior and performance will be more successful if they clearly articulate the competencies (of Figure 2) that are critical to managing technological and innovative changes, and to create value for customers (Hamel and Prahalad 1994, p. 199).

- All the competences are of different but complementary nature as pointed out in Figure 2, and related to firms' explicit and implicit knowledge. In other words, the model suggests direct links between these critical competencies and the knowledge capital of the organization, as was established in other empirical works (Abel 2008).

- This model has the flexibility to consider different levels of competency requirements, for example, person-focused competence, job-focused competence, and role-focused competence, following the proposal of Sengupta et al. (2013).

- The circular rationale is also compatible with a feedback process of complex decision-making under uncertainty. This means that competencies and tools are closely related to the logical or heuristic sequence of the decision-making process (Arciénaga 1995).

- The circular model of Figure 2 makes different approaches possible, according firms' needs or culture: top-down (from strategic thinking down to identifying core competence), bottom-up (from core competence up to solidifying the strategic thinking), internal emphasis (from the resource base to shaping the competitive edge), external adaptation (from environment to examining the fitness of competence) (cf. Yang et al. 2006), or a mix of these approaches.

- Finally, the model also includes innovation in the sustainability and circular economy field. These issues boosted not only by the markets but also by public regulations and local initiatives. Such issues influence both the innovation process and the business models for innovation (Chesbrough and Rosenbloom 2002).

Therefore, the competencies, behavior, and instruments needed for crossing the valley of death require forming a panoply of different combinations of information, knowledge, aptitudes, attitudes, and skills. In this array, the main aspects of expertise include the following: 
- $\quad$ Research information abilities.

- Knowledge of technology tendencies for strategies.

- Knowledge about financial markets and new schemes (for instance, crowd funding prompted by Internet).

- Knowledge about markets' requirement and skills to identify potential customers.

- Knowledge and skills related to managing innovation processes and projects.

- Abilities to make decisions in risky and uncertain conditions.

- Skills for stimulating entrepreneurship in many different organizational situations.

- Capacity for interacting with many different actors for innovating.

- Knowledge and information of environmental regulations.

- New approaches for product design within the circular economy framework.

The questions become: How do the competencies and instruments needed for crossing the valley of death transform into different combinations of information, knowledge, attitudes, and skills? How might they unfold in a learning model? In the following, drawing on an extensive body of learning theories, we present a visual diagram of a learning model and its components, the possible interactions, and overlap of different learning processes, which are necessary for an effective technology and innovation management.

\subsection{Model of Learning in Technology and Innovation Management}

A model is always a carefully selected abstraction of the real world that provides a conceptual structure. As noted by Sallán et al. (2005, p. 11), an object M is a model from a reality R for an observer $\mathrm{O}$, if $\mathrm{O}$ can obtain the answers to the questions about $\mathrm{R}$ by studying $\mathrm{M}$. Learning models specifically provide a framework for organizing learning experiences. In other words, they provide "accurate and useful representations of knowledge that are needed when solving problems in some particular domain" (Gage and Berliner 1998, p. 314).

In our case, models are useful tools to better understand the learning processes at the firm and value chain levels and are key ingredients in understanding and building ecosystems of innovation. They allow at a glance a full picture of the issues related to the management of technology and innovation today, and they could also suggest more questions for our society's next generation. It also describes a systematic procedure for achieving specific learning objectives. The model serves as a guide for learning and implementing the learning activities (OECD 2017, p. 80).

Furthermore, a learning model is a central perspective to understanding competence development (Drejer 2000). In turn, the firms' competitiveness rests largely on the competencies they internally own (Hamel and Prahalad 1994). However, the important organizational issue is that competence development has received little attention (Drejer 2000, p. 207). Our approach to this topic is to consider many ways of learning that could ensure similar conditions in classrooms (e.g., learner-centered and self-reflective initiatives) as those within the firms, for promoting effectively competence development, even for those based on tacit and ill-structured knowledge.

In this sense, there is no unique framework to interpret the concept of competence and its meanings depend highly on the purpose for which it is used (Hoffmann 1999, p. 275; Barnett 1994). In this work, we understand competencies as a set of knowledge, attitudes, and skills (e.g., schemes of perceptions, reasoning, assessment, values, micro-capacities, and aptitudes) necessary to performing effectively a task or an organizational function (Le Boterf 2008; Levy-Leboyer 2003; Perrenoud 2007). The two main meanings of the term refer to the outputs (i.e., results of training or competent performance) or to the inputs (i.e., underlying attributes required for competent performance) (Hoffmann 1999, p. 276). Competencies transmit meanings to the person or group executing the task (Barnett 1994). However, different cognitive levels within competencies produce also discrepancies and biased interpretations (Geliatly 1992, p. 363). 
As we mentioned, based on case studies and literature related to learning, we have summarized different ways of learning that are especially suitable for building capacity and skills for technology and innovation management. The resulting learning model considers the different bottlenecks related to the European Paradox or the innovative gap in Latin America as well as the research gaps. All the components of the model are interconnected into a systemic and circular rationale. Understanding them as qualitative variables, the possible interactions are shown in the following model.

The following Learning Model for Technology and Innovation Management (Figure 3) illustrates the learning model and its components, the possible interactions, and some overlapping among different learning processes (interdependent variables), which are necessary to effectively master competencies in technology and innovation management (dependent variable). This model facilitates the process of understanding the different learning "avenues" in this domain of knowledge because it is a visual expression of the different learning approaches required. This learning model can also help guide the planning of learning strategies and tools to be used. The external circle shows important factors or contexts that influence the learning process in general. The inner circle also shows internal organizational conditions that deeply affect the learning process (see details in Section 5.2).

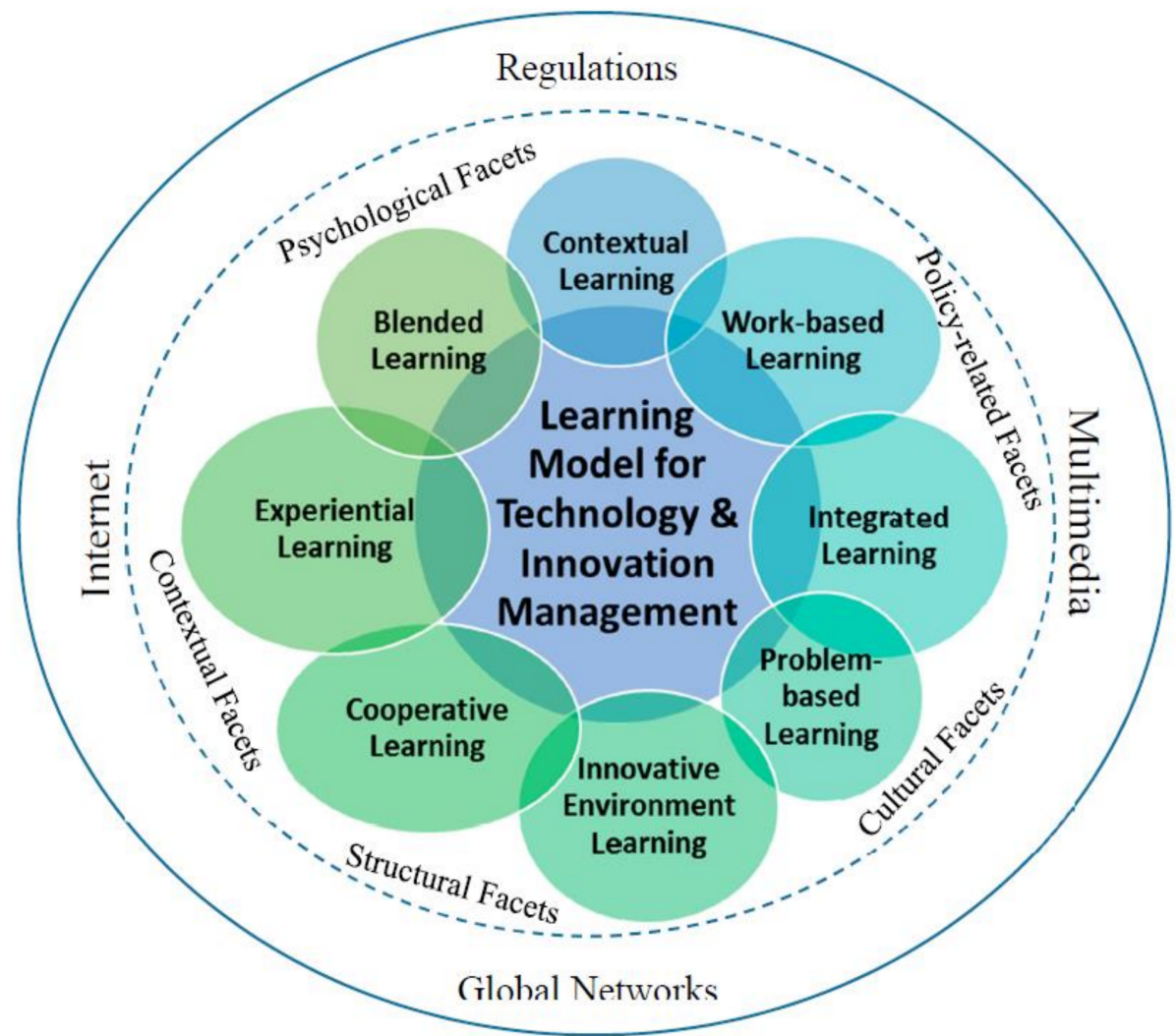

Figure 3. Learning Model for Technology and Innovation Management. Source: own elaboration.

In the following list, we briefly explain each of the learning components or interdependent variables of this model:

1. Cooperative Learning Model: We have already justified the cooperative character of innovation. In a learning approach, this means that co-creation processes are in the frontline analysis (Mytelka and Smith 2002; Nielsen et al. 2012). Group dynamics are also critical for achieving learning conditions and objectives.

2. Experiential Learning: This includes any process that allows firms and their worker (individually or in groups) to apply their knowledge and conceptual understanding to real-world problems 
or innovative situations (Wurdinger and Carlson 2010). The challenges for higher education institutions (HEIs) is how to reproduce innovative experiences in classrooms.

3. Blended Learning: It is consistent with the values and rhythm required for entrepreneurial and organizational learning. Its potential to enhance both the effectiveness and efficiency of meaningful learning experiences has been proven (Garrison and Kanuka 2004).

4. Contextual Learning Model: The innovation process is highly specific to those who originate it (Abernathy and Utterback 1978). History and trajectory matter in terms of innovation. Therefore, learning is very sensitive to the context, and the context is critical for learning in the innovation field. This type of learning is also important to make connections between knowledge and its application at the level of a specific firm. Encouraging this type of learning is equivalent to constructing knowledge and skills specific to each firm and how their workers learn (e.g., individually or in group) learn. A learning environment includes the physical, social, and pedagogical context in which learning occurs.

5. Work-based Learning (WBL): This strategy means learning for work, at work, and through work. It is the systematic connection of classroom experiences with the demands of work. Possible approaches go from minimal workplace guidance to full mentoring support. Bandura $(1999$, p. 25) pointed out that people and groups learn by observing others. At work, this means that learners can extract the principles or rules implicit in the rationale and actions shown by workers in their job routines. Therefore, WBL is grounded heavily on the interdependency between understanding learning, critical reflection, and the identification and development of individuals' and groups' capabilities in a work context.

6. Integrated Learning Model: An integrated model of learning allows students both individually and in groups, to actively search, dig for, and find the concepts and principles of holistic knowledge. Integrated learning is a strategy that tried to include several subjects necessary to manage complex technology or produce creative innovations. For instance, the integration of fact-finding and problem definition can give rise to progressive abstractions of complex problems, particularly those related to decision-making under uncertain conditions. Complex problems consist of interrelated decisions that span multiple domains, paradigms, and perspectives (Liew and Sundaram 2005). Integrated learning associated with decision-making processes is a necessary condition for solving such problems.

7. Problem-Based Learning (PBL): The focus is on using problem solving for learning (Iansiti and Clark 1993). This method encourages firms and workers to learn, think, and solve their own problems. PBL is an educational and training approach whereby the problem is the central base and the starting-point of the learning process. Savin-Baden (2000) identifies five PBL models, most of which are pertinent in the field of technology and innovation management: attainment of knowledge, PBL for professional work, PBL for interdisciplinary comprehension, PBL for cross-discipline learning, and PBL for critical competence. Problems are dependent on the specific organization and can be real-life problems or hypothetical. In both cases, how the problem is selected and framed is crucial to meeting educational objectives and criteria. The problem formulation step emphasizes questions rather than answers (De Graaff and Kolmos 2003, p. 658). The answers, for instance, innovative solutions, are also a learning outcome, which in turn is an integral part of the learning process. Problem-solving learning, particularly when it is practiced in networks or groups, is relevant to building resilient organizations capable of coping with uncertainties (Berkes 2007).

8. Innovative Environment Learning Model: When creating an innovative environment, learning should be able to evolve and adapt innovation practices. This include individual, group, and organizational single- and double-loop learning, assuring metacognition for poor articulated knowledge and practices. The challenge of building an innovative environment is recreating the conditions of an innovative workplace in the classroom (McCoy 2005). 
In summary, the learning model we suggest here identifies important factors, contexts, and facets related to organizational, group, and individual learning in the field of technology and innovation management. These different "avenues" of learning are important to ensure not only learning in complex conditions but also unlearning processes, which is necessary for innovation (see discussion in Section 5.2), and ensures the reproduction or replication of organizational operating conditions to obtain effective outcomes. The integration of different ways of learning could also contribute with some possible explanations to one of the central questions in the management field: Why do some firms learn and innovate more than others? It is interesting to note that the case study showed some of these learning components in each experience, but there is a lack of integration in their pedagogical strategies (see Section 3.2).

\subsection{Synthesis of Findings}

Previous academic schemes (cf. Table 1 in Section 2 and cases in Section 3.2) focused on technology and innovation management show some vulnerabilities. Some of them are due to the changing nature of open and collaborative innovation in the Internet era (i.e., combinatorial innovation, servitization, and innovation beyond a product or service perspective), the lack of enough consideration of uncertainty, the appropriate addressing of globalization impacts on innovation, the ever increasing rate of technology development, the appearance of new ways of financing (i.e., crowdsourcing, new risk capital tools), the combination of new disciplines (i.e., nanotechnology, biotechnology, and IT), the lack of system thinking, an increasing complexity, the focus on big firms forgetting SMEs, and the fast evolution of industry and service environments. All these evolving and dynamic features put increasing demands on competence building at firm and university level. Therefore, all these weaknesses are better reflected in the field of teaching technology and innovation management schemes in HEIs, as documented from case studies (see Section 3.2).

For solving these limitations, based on case studies and literature review, we propose here two interconnected models, whose central objective is to create lasting impact on technology and innovation management, and the learning of this subject. Both models considered these weaknesses either individually (as tools, competences and behaviors) and holistically (as circular systemic models). This approach emphasizes learning and unlearning to keep a rate of individual and collective learning with the rate of technology evolution and innovation process. Both models together provide new understandings for the focal question of how old and emerging facts affects the innovation strategies and technological behaviors of the firms, particularly SMEs.

The two intertwined models provide new insights into the theories and practices of technology and innovation management, particularly on learning complex practices, dealing with uncertain conditions, and internalizing poor articulated know how, tools, and behaviors. Uncertainty is the main link we choose as a strong connection between both models, and we emphasize unlearning old industrial and service paradigm as a key process to keep in phase (i.e., absorptive organizational capacity) with technological evolution rate. In turn, the technology and innovation management model covers old and new issues that are important for decision makers to master, ranging from strategy to problem solving, risk taking to uncertainty management, product designing to intellectual property, co-creation to managing firms' alliances, forecasting and surveillance to evaluating new technologies, transforming processes to learning organizations, product to servitization innovation, forecasting and surveillance to prospective, traditional to innovative financial tools, R\&D management to innovation projects, and sustainability to circular economy production strategies.

Furthermore, in our approach the learning process is no longer limited to learning by doing, learning by R\&D, and even trials and errors, but also learning by interacting (internally and externally). This means to change the focus from internal specialization to learning through collaborative relationships and co-creation with other firms, customers, governments, and non-profit organizations. The learning model (Figure 3) provides concrete examples of "avenues" that use the principles of open 
sharing ideas, technologies and human capital, and performance measurement systems that reward cooperation and collective achievements.

Connected to absorptive capacity at firm level, another important aspect is what "avenues" converge with solving the learning challenges of knowledge and practices poorly articulated, with many ambiguities, at the suitable rate. In turn, these different theoretical and practical learning approaches are essential for a curricular architecture and with other contributions from the academic field (i.e., technology transfer, research agenda, technical assistance), as educational solutions. Besides, in an uncertainty and complexity framework, training competences for the decision process at innovative firms should explore different learning approaches. This framework implies a fuzzy front-end for innovation and organizational changing processes, that could not be managed with competences derived from a one-size-fits-all standard learning process. Instead, different market, organizational, and technological uncertainties could be successfully address with competences provided by different learning processes (i.e., Section 3.2, cooperative learning, experiential learning, blended learning, contextual learning, WBL, integrated learning, PBL, and innovative environment learning). Finally, in the field of organizational culture, learning has to take into account another important feature: innovation is more of an attitudinal than a structural change. Thus, training of behavior is also an important aspect of technology and innovation management.

\section{Discussion}

Broadly speaking, the main objective of this study is to analyze different cases from Europe and Latin America to synthetize a model of technology and innovation management, and then derive from that knowledge base a new model of learning for higher education. Discussions in both cases emphasize the contributions from an educational perspective.

In the first case, experiences seem to point to solutions based on cooperative innovation, as well as ways to identify product, process, and service opportunities emerging from an almost global context. Furthermore, the competencies for transforming ideas into a strategic project, the know-how to provide entrepreneurship training to innovative participants, the know-how to finance such new opportunities and how to interact for solving environmental problems with new tools and rationale are also part of the discussion. These are the answers we are looking for to deal with the creation of capacities in managing innovation, while closing the innovative gap, in a world of uncertainty, sustainability, and complexity.

In the second case, learning strategies also involve capacity building on complexities, knowledge valorization, risk taking, and environmental issues. An interdisciplinary method is necessary to capture value from the innovation process, when approaching R\&D knowledge production and valorization. The interactive character of the innovation process also imposes the need to address the capacity to manage different stakeholders' perspective in cooperative and co-creative innovation. To enrich the learning process, sustainability approaches are also required. System thinking, complexity and uncertainty management, and strategic vision are also in the very frontline of analysis. Given the particularities of both models, in the following, we first discuss them separately but with cross references, and at the end of Section 5.2., we analyze them in relation to their main connection.

\subsection{Discussion of the Model of Technology and Innovation Management}

The innovation gap, or the previously mentioned European Paradox, constitutes a complex problem space with many of the variables listed above, most of which are systemic factors with circular causations among each other and follow complex decision-making processes. Furthermore, as we mentioned in Section 2, uncertainty is another important condition that strongly affects technology and innovation management (Tidd 2001; Shane 2008; White and Bruton 2011). This condition was poorly incorporated in the training agenda of the cases studied and in the specific literature reviewed above, except for Tidd et al. (2005). The main common variables in Table 1 can be put in terms of interrelated competencies and tools: availability and management of financial resources; competencies 
in the field of innovation and project design; intellectual property rights management, technological and commercial risk assessment, innovation management; capabilities and attitudes for coping with uncertainties; technology transfer agreements; management of innovative projects; suitable knowledge dissemination; knowledge management; scouting of technology solutions; and marketing of technologies and new products.

All these variables require two things to be operative in a virtuous circle: combinatorial capacity building and innovative interactions among each other. All of these variables are primarily focused within the field of technology and innovation management. In the following paragraphs, every competence, activity, and tool will be discussed when necessary to narrow or broaden their meaning (because many of them are self-explained). This research consider these components both individually and holistically (the circular systemic model). Without a specific order, priority, or hierarchy, the following list includes all the variables of our model to be described:

i. Strategic Management (of innovation and technology).

ii. Product, Process, Servitization, and Organizational Innovation.

iii. Network and Information Technology (IT) Management.

iv. Risk Capital and Financing Management.

v. Forecasting, Prospective and Surveillance.

vi. Entrepreneurial Management.

vii. Talent and Creativity Management (including knowledge management).

viii. Circular Economy, Responsible and Sustainable Innovation.

ix. Intellectual Property Rights (IPR) Protection and Exploitation.

x. R\&D Management.

xi. Technology Transfer.

xii. Project Management.

xiii. Problem Solving.

xiv. Uncertainty and Risk Management.

xv. System Thinking.

xvi. Complexity Management.

Initially, the management of technology and innovation focuses on strategic innovation for sustainability and a competitive advantage, but strategy could also be competitive positioning (Porter 1996). Typically, strategies involve complementing the need for new markets, products, new services, and new business models. However, it also integrates what is sometimes called adaptive innovation, which is the capacity for cost reduction, quality improvement, and increasing productivity. Here, an organization concern is focused on current operations, with emphasis on innovation for value adding adaptations to current processes. For long-term vision, it is required competence in Strategic Management (of innovation and technology).

There are problems with competencies for identifying product, process, and service opportunities that can emerge from academic R\&D, particularly in new fields such as nanotechnologies, biotechnology, or IT (Information Technologies). Additionally, many cultural and marketing aspects, which are key determinants for launching new products, new processes, and new services, are not totally considered for taking advantage of these opportunities. Certainly, innovation is pervasive to all organizational activities and managing it is a currently big challenge. Competencies such as product, process, servitization, and organizational innovation as well as R\&D management are keys to meeting such challenge.

SMEs, particularly in technology and innovation management, deserve some comments. One important point in the management style of almost all SMEs in less-favored regions is the central role of the owner-entrepreneur, who is sometimes assisted by relatives or technical personnel, follows the prevailing intuition-based management style by focusing attention on daily problems rather 
than on wide-ranging problems or strategic planning. Usually, this management style is paternalistic and autocratic. This role is also crucial in innovative small firms, as it is reflected in some studies (Raffa and Zollo 1994). The capacity of the entrepreneur to establish relationships with professionals is required to sustain the individual firm's innovative capacities. Although the innovation concepts or perceptions vary from one country to another, bad management practices, particularly in SMEs, have many qualities in common elsewhere. For example, managers who focus on the aforementioned daily process will not achieve innovative results, which are usually realized through sustained medium- and long-term efforts. This imbalance attention ends with scarce or no managerial interest in innovation, and discourages innovation practices among the employees. Therefore, learning to use tools for managing time and priorities could be helpful for managers everywhere, by positively influencing daily routines. The competencies necessary for this managerial style are forecasting, prospective and technological surveillance, entrepreneurial management, networks, and IT management.

Moreover, in technology-contingent SMEs, innovation is primarily dependent on the purchase of machinery and equipment, which is constrained by the SME's financial shortages. Is innovation better managed by resource scarcity? There is a threshold for resources, and below this threshold innovation is impossible. However, what is the value for this threshold? It is important to highlight the lack of capabilities as well as the scarcity of resources. One important added problem for technology and innovation management at the SMEs level is the firm's limited ability to identify its own demand for technology, training, etc. Problem solving is certainly a suitable skill for this range of issues.

The management of innovation should also include measures to reduce the accountability for conflicts of interest. Nearly all current performance management models are stacked against innovation because the workers are not rewarded for taking chances on doing something different, which involves accepting failure as a possibility of exploration, learning, and improving.

In the majority of performance management models, employees are only held accountable for their individual output, in this way preserving the status quo. Current performance management approaches are largely on results (Grumana and Saksb 2011). It is not enough that managers tell workers to be innovative; without changes in the structure or the tasks that workers perform, innovation will not happen. For these problems, we propose training competences in talent and creativity, problem solving, and uncertainty and risk management.

Regarding complexity management, understanding the dynamics of innovation and performance in complex systems is a key competence. Design, coordination, and management are central tasks in managing and organizing complex systems. Some proposals to solve designing focus on modularity rationale (Ethiraj and Levinthal 2004). Systems thinking is also considered critical in handling the complexities facing the world in the near future (Arnold and Wade 2015, p. 669). Much of the art of systems thinking involves the ability to represent and assess dynamic complexity, both textually and graphically. Specific systems thinking skills include understanding the linkage between the interaction of agents over time and the system behavior; identified feedback processes, delays, nonlinearities, stock and flow relationships, and boundaries of mental models to explain patterns in a system behavior (Sweeney and Sterman 2000).

The field of culture and leadership is another important aspect of the management of technology and innovation. Leaders cannot simply create a new culture, even in new venture firms, because culture is by definition a shared phenomenon. Although they can play a key role in shaping it, leaders seldom create the organizational culture completely by themselves, especially in a well-established organization whose underlying assumptions are formed through years of tradition and success.

Culture is a pivotal point, and a systemic factor in any discussion about innovation. Culture is at the core of the organization itself, at the basis for how the organization functions and undertakes its mission. A culture of innovation and creativity requires organizations to break down functional barriers, making innovation everyone's job. In Christensen's disruptive innovation theory, a culture manifests itself as resources, processes and priorities (Christensen 1997). For addressing culture 
and strategic issues, we propose system thinking and complexity management, even though these competencies apply to other organizational issues.

Creative environments within organizations can be established by implementing four key components; a culture with clearly-shared understanding of identity and purposes; effective communications and suitable relationships between the firm's members; knowledge-sharing circuits and networks; and recognizing members' contributions and rewarding them. Hierarchies have a central role within organization, which is related to the first three components. They can allow, enhance or obstruct the flow of ideas. In this sense, it is important to create and implement an effective organizational design and management practices that include nonhierarchical attitudes when dealing with the new ideas and suggestions. A creative environment involves much more than giving freedom to the workers to arrive by chance at a valuable result. Creativity, like any other process, requires the management of activities within a suitable framework to operate effectively. It is equally important for organizations to minimize the impact of hierarchies so that a seamless flow of ideas is possible and creates new practices that include nonhierarchical attitudes when dealing with new ideas and suggestions. However, some questions are still open: Are collaborative networking processes manageable? Talent and creativity management, as well as networking and IT management, are crucial for creative environment.

Other ways to facilitate a creative environment within which innovation can flourish include cultivating, encouraging, and supporting internal entrepreneurship. This approach recalls what Jack Welsh termed the four "Es" and one "P": energy, energize, edge, execution, and passion (see, for instance, Krames 2005). The disciplines of creativity, organizational behavior, environment, individual behavior, and the physical environment have also played a major role in building creative contexts (McCoy 2005). It is worth mentioning that the last component of a creative environment is paying attention to the physical environment as a context enhancing creativity, and the management of innovation activities (Moultrie et al. 2007, p. 53).

Innovation activities of all kinds are typically conducted by means of projects. Thus, project management is another competence with a significant impact on technology and innovation management. Innovation processes and new product development projects are managed similarly in many organizations (Lopes et al. 2012). Instead of a single project, even smaller organizations manage many projects that compete for scarce resources. Therefore, it appears there is the management problem of multiple interdependencies between projects, including resource requirements and knowledge flows. Obtaining effective innovation results is greatly dependent from solving the bottlenecks that appear with resources and knowledge flows in single or cooperative strategies (Brunner et al. 2008, p. 217).

In smaller and technology-contingent firms, innovation projects are usually informal in nature and reactive or adaptive to context change. This means that there is no formal allocation of resources to them; projects are the result of problem-solving processes, and the personnel involved are not specifically assigned to innovation tasks but related to the problem being solved (i.e., quality, maintenance, production, sales, etc.), (Arciénaga et al. 2015). These skills are rather different from those required in formal project management. Point of departure is different in both cases (e.g., formal and informal projects). Problems are poorly defined solutions seeking clarity (i.e., vision), and projects are a fully defined solution seeking implementation (i.e., realization). Therefore, each project management style calls for very different competencies. Project management training must address these differences.

Additionally, there is a considerable body of knowledge that innovation and learning work best when they are an organization-wide phenomenon (particularly for SMEs), instead of only confining them to R\&D or design departments (Keskin 2006). Equally, there is evidence for innovation actions that suggests a bottom-up approach works better than a top-down approach (Gessinger 2009), particularly for flourishing a co-creation process among organization members. However, many questions remain to be answered: Are "bottom-up" exploration and findings more effective than the "top-down" strategy? Can technology and innovation management tools improve findings? R\&D management is a necessary competence here but also different coordination styles for co-creation. 
It is important to remark that sustainability is a common problem in EU, LA, and globally, which is closely related to the innovation field. Our approach to technology and innovation uses the framework of sustainability and circular economies (i.e., concepts, business models, and instruments). Concerning sustainability, a circular economy is sought by most countries because it promotes resource productivity with the aim of reducing wastes and avoid pollution (cf. Murray et al. 2017). Industrial products and systems should be designed to close the loop by recycling and reusing post-consumer waste to make new products. This innovative approach must be fostered by training and education, especially among manufacturing enterprises, because innovators need to unlearn old industrial paradigm and learn new ones. Well-prepared managers and local developers are fundamental in implementing this responsible innovation style. Thus, a particular emphasis must be placed on learning how to transform knowledge into concrete products and services within a circular economy through responsible innovation and sustainability, which are also required competencies for advancing in technology and innovation management.

Finally, innovation and creativity are beyond a product or service perspective because considerable innovations are outside these categories. The innovation process involves not only new way of doing but also new ways of thinking, making arrangements for interactions, visions for perceiving, formulas to deploy strategies or doing business, and methods for organizing. In the field of organizational culture, innovation is more of an attitudinal than a structural change. Thus, training of behavior is also an important aspect of technology and innovation management.

\subsection{Discussions on the Model of Learning in Technology and Innovation Management}

As mentioned above, another approach to the issues involved in the technology and innovation management field is to address them as competencies and behaviors that can be incorporated into a model of learning. Considering the morass of definitions for technology and innovation management and the need for clear concepts and uses of learning models, an implementation framework for the learning model becomes self-evident. This alternative seems to provide a more sustainable base and a direct connection for future graduate-level training and education. In the next paragraphs, we discuss the main issues related to a learning model, possible strategies to solve these issues, and the most important characteristics of such model (i.e., Figure 3), stressing educational perspective in the analysis.

Innovation process is inextricably connected with organizational learning, as was very well demonstrated in the literature. An interesting summary with well documented cases that include the two regions (EU and LA) was published in OECD (2008), where the different approaches, methods, and mechanisms for this virtuous relationship seem to culminate in forming competencies and developing pertinent behaviors.

Thus, our model of learning includes different ways to obtain a panoply of competencies to solve different technology- and innovation-management issues at the firm level, particularly for SMEs. The model also addresses innovation challenges related to new innovative relationships and product opportunities emerging from traditional sectors, and from nanotechnology, biotech and IT fields, with particular requests related to environment and sustainability problems. Some of the main questions or issues that need to be solved or addressed in any learning model in this field are:

- How are competence requirements for technology and innovation management identified at the firm level, particularly SMEs?

- What are the innovation challenges related to product opportunities emerging from traditional and from new fields (e.g., nanotechnology, biotech and ICT)?

- What are the most effective methods for coping with risky and uncertainty conditions, and what abilities are necessary?

- Which demands are required for solving the environmental and sustainability problems linked to technology and innovation management? 
- How can new competencies be learned for transforming ideas, tools, competencies, and behaviors into an innovation project?

- Which types of practical knowledge should be provided in entrepreneurship training to innovative participants?

- Which types of expertise are necessary to finance new creative or innovative opportunities?

- How can we learn to interact in a manner that promotes solving environmental problems with new tools and rationales?

- What competencies are crucial for knowledge intensive entrepreneurship and business?

- How can learning promote geographical ecosystems of innovation?

- How is the human learning process changing with the evolution of technology?

Any solution to address the complex problem of organizational and academic learning should be a systemic and intelligent answer, which includes the following approaches:

- System thinking based on an interdisciplinary scientific method for approaching learning issues, that also consider different paths for learning.

- A hands-on approach to the learning process.

- A focus on developing complex and interrelated competences.

- An eclectic approach comprised of top-down, bottom-up, and networked rationales.

- Skills, tools, and attitudes for managing uncertainty and risk taking when evaluating any kind of innovative situation.

- Inter-sectorial experiences (e.g., public, private, different socio-economic sectors) for enriching and validating tools and methods.

- Cross-cultural and multi-stakeholder participation and collaboration for ensuring diversity as a pre-requisite of innovation.

- An emphasis on how to transform knowledge into concrete marketable products and services.

Therefore, the results presented in Section 4.2. can be characterized as a proposed alternative model of learning in technology and innovation management based on an education-action approach, a cooperative innovation model related to many facets (e.g., new product development, project management, circular economy, and sustainability), contexts, and new practices of learning in HEIs. As a complement, this learning model includes particular components for training competencies in SMEs. A pre-requisite is the development of a methodology for identifying such competences and needs in innovation. In turn, this methodology is an essential base for developing and testing curricular design, which is the key platform in graduate educational requirements. As common value, the different learning approaches also have the possible use of online tools for computer simulation and result-based training, stimulating diverse learning in technology and innovation management. These e-tools can contribute via other functions such as providing e-services to and promoting innovation behaviors within SMEs.

The diversity of cases for different ways of learning is another important basis. Learning cases present a greater learning potential when they are associated with a cooperative innovation approach because discussing and sharing results can contribute to creating communities of practice. Furthermore, learning communities require a collaborative network to develop a more comprehensive and complex framework for methods and techniques (Wenger et al. 2002). Furthermore, learning based on diversity in partners and cases may create more openness for the complexity of organizational needs (particularly in SMEs) and enhance visions of participanting agents for the possible participation of other stakeholders (e.g., policy makers, local developers, consultants, entrepreneurs, etc.). This combination also contributes to a better understanding of technology and innovation management. The diversity in cultures and partners, open for different innovation concepts, adds value to expected pedagogical results by developing a robust and suitable method for curricular design. 
Regarding learning issues at the firm level, March and Simon (1958) first posed the construct of organizational learning as the main argument to refute the claim of neoclassic economic models that organizational decision-making is uniquely determined by environmental constraints, particularly price. The concept of organizational learning is not only an interdisciplinary knowledge space dominated by scholars (Easterby-Smith 1997); it has also attracted the analysis and participation of educators, consultants, and managers in the business world (Dodgson 1993). Without this interdisciplinary approach, it seems very difficult to reach a more profound understanding of the complexity and variety of organizational learning processes and models. Many scholars recognize that there is more than a single framework or model in understanding organizational learning process. Therefore, researchers have tended to record many aspects of organizational learning, in their effort to develop integrative conceptual frameworks.

In this work, we focus on organizational learning rather than the cognitive perspective of such a process because the former is linked directly to organizational change and innovation and the latter is mainly related to knowledge management. Following Lipshitz et al. (2002), this line of reasoning leads to an integrated approach to a learning process framework, consisting of five complementary facets: structural, cultural, psychological, related-policy, and contextual. The structural facet is necessary but not sufficient for generating productive organizational learning. The others are additional facets of organizational learning and their presence or absence can facilitate or inhibit learning processes.

Finally, uncertainty is the main link we identified as a strong connection between both models. Uncertainty is a general factor that affects not only technology and innovation management but also the learning process at the organizational level. When coping with uncertainty, the ability to unlearn patterns or criteria used until now is essential to making room for innovations. Without unlearning, old criteria or patterns drive and mold new information or ideas into old models. Today, unlearning is a required competence for radical change in the structure of our knowledge, which is not necessarily compatible with extant models (Bauman 2007).

Unlearning is critical for deep changes; it involves throwing away or temporarily putting aside parts of individual and organizational patrimony or concepts learnt in the past, to create space for new learning. In this sense, a learning process that is comprised of different unlearning-learning stages supports the innovation process (Akgun et al. 2007; Pighin and Marzona 2011). Therefore, organizational unlearning, learning, and relearning have synergistic effects on the innovation process and dynamic knowledge management (Zhao et al. 2013), particularly in situations involving uncertainty. Under these last conditions, the organizational learning approach consists of multiple stages, some of them in parallel, some of them trial and error: learn, operate, learn, change, unlearn, relearn, operate, learn, change, unlearn, relearn, and operate, in a repeated process.

How can we ensure that learning and unlearning can interact with uncertainty conditions in a training program? According to Berkes (2007, p. 284), two important features are central for the coping with uncertainty: the irreducible nature of uncertainty in complex systems and the question of vulnerability. The first implies the necessity of an attitude of living with change and uncertainty, and the second requires building resilient organizations to reduce vulnerability. When considered together, the two models introduced (Figures 2 and 3) posed three alternatives for coping with uncertainty. First, the convergence of different "avenues" of learning will better ensure that learning-unlearning processes will occur effectively at individual, group or organizational levels, and that cognitive abilities will link effectively with superior decision-making under risky and uncertain situations. Second, some important tools such as risk-constrained methods are a necessary decision support, especially in the technology and innovation field. Third, building organizational resilience is another effective answer to manage change characterized by random and inscrutable risks (Berkes 2007).

\section{Conclusions}

This research has some limitations in generalizability. It focusses on EU and LA regions and the higher education system. Further studies may consider the applicability of the findings in other regions 
and other education and training levels. Another limitation is the case study-based methodology, and there is a need for further empirical deductive validations of the propositions and relationships observed in the two models suggested herein. Both models, technology and innovation management and organizational learning, are primarily designed to understand the links with curricular design. They need to be taken together when interpreting the results.

Few studies observe both the value attributed to technology and innovation management and organizational learning to guide the curriculum design at the graduate level in higher education. Therefore, curriculum design is the ultimate rationale behind all the research. This analysis contributes to the debate on the adjustment and development of competencies and tools in the field of technology management and the link between this process with suitable learning practices and curricular design.

In terms of practical implications, the paper may support firms, universities, and other agents (e.g., local governments, managers of TTOs, science parks, and innovation agencies) to enhance the complex processes of human capital training in the field of technology and innovation management, particularly for SMEs and LA stakeholders.

As mentioned previously in the introduction, this paper is the background study for designing a proposal within the European initiative's Erasmus+ Program. This proposal was selected to be financed, and we briefly present the most important preliminary aspect of this project, to contribute to the meaning and understanding of the results shown in Section 4.

EULA-GTEC project's specific objectives are:

- Increase the quality and quantity of human capital devoted to knowledge management, technology transfer, financing innovative start-ups, and solving sustainability problems, particularly in SMEs.

- Train and educate new professionals with new competencies and behaviors, capable of discovering new opportunities, harmonizing technology transfer, developing research projects, managing financing schemes, introducing sustainability solutions and circular economies (i.e., concepts, business models, and instruments), fostering society and market interactions, and innovation in various fields.

- Develop an IT platform with online tools which will allow the launching and implementation of a master's program for the education and training of technology and innovation managers.

- Create an antenna system closely connecting the master's degree to industry by identifying firms' innovative needs to promote their training and graduate's employability within a blended learning approach.

The project intends to contribute significantly to higher education by proposing a specific master's degree program to develop innovative managers, researchers, and local developers as well as provide a direct connection between industry and society using a framework of blended learning approach. The aim of the master's program is primarily to allow SMEs and other types of companies or institutions to identify good practices and new behaviors to face innovation challenges. The students who graduate shall be capable of dealing with innovation in traditional sector's products as well as others with the most advanced technologies. Particular attention will be paid to training competencies for complexity, uncertainty, environmental problems, and circular economy challenges to achieve sustainable solutions.

The project faces the innovation challenge by developing a master's degree with scientific, systemic, and interdisciplinary rationales. It also includes a hands-on perspective by focusing on the training of behaviors and the creation of specific competencies and tools, including those needed for circular economies and complex and uncertain situations. Diversity in cultures, scientific areas and partners, open for many different innovation approaches, will also add value to expected results by developing a shared international solution.

The project will respect an appropriate gender balance and will place this as a standard item in the master implementation agenda. Special attention will also be paid to the involvement of early-stage teachers and researchers. An important means to achieve the goals of the project is to encourage 
the participation of young professors and scientists and external stakeholders, particularly SMEs. The organization of training schools will not only ensure the training of new generations of professors and researchers but will also increase the possibilities for them to meet consolidated researchers and professors in their fields of expertise, and ultimately the consortium as a whole. Thus, capacity-building purposes will be ensured.

To summarize, for training and academic experiences, LA countries and EU's less-favored regions require a better understanding of the dynamics of innovation and performance in complex systems. In parallel, another important issue is what is the best way to introduce technology and innovation management concepts, strategies and practices into enterprises, regions and local authorities. Furthermore, in the case of SMEs, their decision-making process needs special attention, particularly in small family owned firms. Here, the owner or entrepreneur represents the central figure. He or she endows the SME with his or her own personal and determinant attitude to technology and innovation management, and gathering of information is usually crisis-driven in SMEs. Finally, the changing nature of technological processes, innovation processes, and the evolution of the context, in particular the globalization phenomenon, have great influence on the academic proposal in the field of technology and innovation management.

One of the major obstacle is devising academic programs which reflect the needs of the majority rather than the minority of the firms. This is crucial in regions where there is little innovation and relatively few high-tech firms. Although supporting a few high flyers or dynamic firms can be highly productive, it is the many firms that will ultimately generate most new jobs. Micro SMEs are often left out of support measures. In some of the less-favored regions, they represent a major portion of the productive sector. It is interesting to note that in Japan the policies towards SME modernization also embrace micro SMEs. However, many academic schemes focus on providing tools and information for upgrading technological and entrepreneurial competencies, but fail to consider the requirements and learning capacity of the firm. If the firm does not develop the latter, it stunts the potential for positive, cumulative, and dynamic growth from within.

Therefore, the development of good technology and innovation management in higher education requires a holistic and systemic approach to initiatives over the whole spectrum of innovation and technological diffusion, strategy, financing, marketing, and above all the decision-making abilities to ensure competencies strategically focused on firms' choices, which supports and nurtures employment and profitability.

Acknowledgments: The authors received support from their respective universities and the European Program Erasmus+. We thank anonymous reviewers for comments that greatly improved the manuscript. Remaining errors are ours.

Author Contributions: All authors contributed intellectually and significantly to the paper.

Conflicts of Interest: The authors declare there are no conflict of interest.

\section{References}

Abel, Marie-Hélène. 2008. Competencies Management and Learning Organizational Memory. Journal of Knowledge Management 12: 15-30. [CrossRef]

Abernathy, Williams J., and James M. Utterback. 1978. Patterns of Industrial Innovation. Technological Review 80: $41-47$.

Adams, Richard, John Bessant, and Robert Phelps. 2006. Innovation Management Measurement: A Review. International Journal of Management Reviews 8: 21-47. [CrossRef]

Akgun, Ali E., John C. Byrne, Gary S. Lynn, and Halit Keskin. 2007. Organizational unlearning as changes in beliefs and routines in organizations. Journal of Organizational Change Management 20: 794-812. [CrossRef]

Anderson, Timothy R., Tugrul U. Daim, and Francois F. Lavoie. 2007. Measuring the Efficiency of University Technology Transfer. Technovation 27: 306-18. [CrossRef]

Andreasen, Lars, Benjamin Coriat, and Raphael Kaplinsky. 1995. Europe's Next Step: Organisational Innovation, Competition and Employment. Brussels: Routledge. ISBN 978-0-7146-4630-5. 
Annavarapu, Ramesh N. 2016. Investigations on the complex decision-making process using choice based probabilistic models. International Journal of Advanced Information Science and Technology 5: 1-4.

Arciénaga, Antonio A. 1995. Technology Management in Less Favored Regions. Paper presented at European Conference "Managing Science and Technology in the Regions", Wallonia, Belgium, June 8-10.

Arciénaga, Antonio, Luis Orlandi, Pablo Aguerre, Leonardo Rey, Claudio Borrás, Marcelo Elola, and Martín Luque. 2015. INNOLAB - Innovación en las Empresas Liderada o Dinamizada por Trabajadores de Media y Baja Calificación: Clave Central para un Modelo Argentino de Innovación (INNOLAB-Entrepreneurial Innovation Leads by Low and Medium Qualified Workers: Central Key for and Argentine Model for Innovation). Paper presented at XVI Seminario Latino-Ibero-Americano de Gestión Tecnológica ALTEC 2015, Porto Alegre, Brazil, October 19-22.

Arnold, Ross D., and Jon P. Wade. 2015. A Definition of Systems Thinking: A systems approach. Procedia Computer Science 44: 669-78. [CrossRef]

Arocena, Rodrigo, and Judith Sutz. 2010. Weak Knowledge Demand in the South: Learning Divides and Innovation Policies. Science and Public Policy 37: 571-82. [CrossRef]

Bandura, Albert. 1999. Social Cognitive Theory: An Agentic Perspective. Asian Journal of Social Psychology 2: 21-41. [CrossRef]

Barnett, Ronald. 1994. The Limits of Competence: Knowledge, Higher Education and Society. Bristol: Open University Press.

Bauman, Zygmunt. 2007. Liquid Times: Living in an Age of Uncertainty. Cambridge: Polity Press. ISBN 978-0-7456-3967-3.

Berkes, Fikret. 2007. Understanding uncertainty and reducing vulnerability: Lessons from resilience thinking. Natural Hazards 41: 283-95. [CrossRef]

Beuren, Fernanda Hänsch, Marcelo Gitirana Gomes Ferreira, and Paulo A. Cauchick Miguel. 2013. Product-service systems: A literature review on integrated products and services. Journal of Cleaner Production 47: 222-31. [CrossRef]

Bhalla, Gaurav. 2011. Collaboration and Co-Creation. New Platforms for Marketing and Innovation. Reston: Springer Science+Business Media, LLC. ISBN 978-1441970817.

Bigliardi, Barbara, and Francesco Galati. 2016. Which factors hinder the adoption of open innovation in SMEs? Technology Analysis \& Strategic Management 28: 869-85. [CrossRef]

Bravo-Ortega, Claudio, and I. García. 2007. Cerrando la Brecha Innovativa Latinoamericana: ¿Qué podemos aprender de Corea, Israel y Finlandia? (Closing the Latin-American Innovative Gap: What can we learn from Korea, Israel and Finland?). Serie Estudios Socio-Económicos 35; Santiago de Chile: Corporación de Estudios para Latinoamérica. ISSN 0717-5264.

Brunner, David, Lee Fleming, Alan MacCormack, and Darren Zinner. 2008. R\&D Project Selection and Portfolio Management: A Review of the Past, Description of the Present, and a Sketch of the Future. In Handbook of Technology and Innovation Management. Edited by Scot Shane. New York: Wiley \& Sons, pp. 215-38, Chapter 7. ISBN 978-1-4051-2791-2.

Chesbrough, Henry, and Richard S. Rosenbloom. 2002. The Role of Business Model in Capturing Value from Innovation: Evidence from Xerox Corporation's Technology Spin-off Companies. Industrial and Corporate Change 11: 529-55. [CrossRef]

Christensen, Clayton. 1997. The Innovator's Dilemma. Boston: Harvard Business School Press. ISBN 0-87584-585-1.

Cokely, Edward T., and Colleen M. Kelley. 2009. Cognitive abilities and superior decision making under risk: A protocol analysis and process model evaluation. Judgment and Decision Making 4: 20-33.

Crespi, Gustavo, and Pluvia Zuniga. 2012. Innovation and Productivity: Evidence from Six Latin American Countries. World Development 40: 273-90. [CrossRef]

De Graaff, Erik, and Anette Kolmos. 2003. Characteristics of Problem-Based Learning. Journal of Engineering Education 19: 657-62.

Debackere, Koenraad, and Reinhilde Veugelers. 2005. The role of academic technology transfer organizations in improving industry science links. Research Policy 34: 321-42. [CrossRef]

Dodgson, Mark. 1993. Organizational Learning: A Review of some Literatures. Organization Studies 14: 375-94. [CrossRef]

Dogson, Mark. 2000. The Management of Technological Innovation. Oxford: Oxford University Press. ISBN 978-0198775362. 
Dosi, Giovanni, Patrick Llerana, and Mauro Sylos Labini. 2006. The Relationships between Science, Technologies and their Industrial Exploitation: An illustration through the myths and realities of the so-called 'European Paradox'. Research Policy 35: 1450-64. [CrossRef]

Drejer, Anders. 2000. Organizational Learning and Competence Development. The Learning Organization 7: $206-20$. [CrossRef]

Dubois, Anna, and Lars-Erik Gadde. 2002. Systematic combining: An abductive approach to case research. Journal of Business Research 55: 553-60. [CrossRef]

Easterby-Smith, Mark. 1997. Disciplines of Organizational Learning: Contributions and Critiques. Human Relations 50: 1085-113. [CrossRef]

Eisenhard, Kathleen M. 1991. Better Stories and Better Constructs: The Case for Rigor and Comparative Logic. Academy of Management Review 16: 620-27.

Eisenhardt, Kathleen M., and Melissa E. Graebner. 2007. Theory Building from Cases: Opportunities and Challenges. Academy of Management Journal 50: 25-32. [CrossRef]

Ethiraj, Sendil K., and Daniel Levinthal. 2004. Modularity and innovation in complex systems. Management Science 50: 159-173. [CrossRef]

European Commission. 1995. Green Paper on Innovation. Luxembourg: European Commission.

Eveleens, Chris. 2010. Innovation management; a literature review of innovation process models and their implications. Working Paper HAN University of Applied Sciences 23: 112-121.

Fernández-Esquinas, Manuel, Carmen Merchán-Hernández, and Oihana Valmaseda-Andía. 2016. How effective are interface organizations in the promotion of university-industry links? Evidence from a regional innovation system. European Journal of Innovation Management 19: 424-42. [CrossRef]

Friedman, Joseph, and Jonathan Silberman. 2003. University Technology Transfer: Do incentives, management, and location matter? The Journal of Technology Transfer 28: 17-30. [CrossRef]

Gage, Nathaniel, and David Berliner. 1998. Educational Psychology, 6th ed. Princeton: Houghton Mifflin Company. ISBN 978-0395797945.

Galati, Francesco, Barbara Bigliardi, Alberto Petroni, and Giuliano Marolla. 2017. Which Factors are Perceived as Obstacles for the Growth of Italian Academic Spin-offs? Technology Analysis \& Strategic Management 29: 84-104. [CrossRef]

Garrison, D. Randy, and Heather Kanuka. 2004. Blended learning: Uncovering its transformative potential in higher education. The Internet and Higher Education 7: 95-105. [CrossRef]

Geliatly, Angus. 1992. The Misleading Concept of Cognitive Competences. Theory Psychology 2: 363-90. [CrossRef]

Gessinger, Gernot H. 2009. Materials and Innovative Product Development: Using Common Sense. Burlington: Butterworth-Heinemann. ISBN 978-1-81617-559-3.

Grumana, Jamie A., and Alan M. Saksb. 2011. Performance management and employee engagement. Human Resource Management Review 21: 123-36. [CrossRef]

Hamel, Gary, and Coimbatore K. Prahalad. 1994. Competing for the Future. Cambridge: Harvard Business School Press. ISBN 978-0875847160.

Hayter, Christopher S., and Mary K. Feeney. 2016. Determinants of external patenting behavior among university scientists. Science and Public Policy 44: 111-20. [CrossRef]

Hoffmann, Terrence. 1999. The meanings of competency. Journal of European Industrial Training 23: $275-86$. [CrossRef]

Horn, Paul M. 2005. The changing nature of innovation. Journal Research-Technology Management 48: $28-31$. [CrossRef]

Hüllermeier, Eyke. 2007. Case Based Approximate Reasoning. Dordrecht: Springer. ISBN 978-1-4020-5695-6.

Iansiti, Marco, and Kim B. Clark. 1993. Integration and Dynamic Capability: Evidence from Product Development in Automobiles and Mainframe Computers. Harvard Business School Working Paper No. 9304 7; Boston: Harvard Business School.

Ishizu, Saori, Mizuki Sekiya, Ken-ichi Ishibashi, Yumi Negami, and Masafumi Ata. 2008. Toward the responsible innovation with nanotechnology in Japan: Our scope. Journal of Nanoparticle Research 10: 229-54. [CrossRef]

Jiménez-Jiménez, Daniel, and Raquel Sanz-Valle. 2011. Innovation, organizational learning, and performance. Journal of Business Research 64: 408-17. [CrossRef] 
Kaldor, Nicholas. 1961. Capital Accumulation and Economic Growth. In The Theory of Capital. Edited by F. A. Lutz and Douglas Hague. New York: International Economic Association \& Macmillan, pp. 177-222. ISBN 978-1-349-08452-4.

Keskin, Halit. 2006. Market orientation, learning orientation, and innovation capabilities in SMEs: An extended model. European Journal of Innovation Management 9: 396-417. [CrossRef]

Kim, Linsu, and Richard Nelson. 2000. Technology, Learning, and Innovation. Experiences of Newly Industrialized Economies. Cambridge: Cambridge University Press. ISBN 978-0521779876.

Krames, Jeffrey A. 2005. Jack Welch and the 4 E's of Leadership: How to Put GE's Leadership Formula to Work in Your Organization. East Windsor: McGraw Hill. ISBN 978-0-07-145780-4.

Lall, Sanjaya. 2000. Technological change and industrialization in the Asian newly industrializing economies: Achievements and challenges. In Technology, Learning, and Innovation: Experiences of Newly Industrializing Economies. Edited by Linsu Kim and Richard R. Nelson. Cambridge: Cambridge University Press, Chapter 2, pp. 13-68.

Le Boterf, Guy. 2008. Repenser la Compétence. Pour Dépasser les Idées Reçues: 15 Propositions. Paris: Éditions d'Organisation-Groupe Eyrolles. ISBN 978-2-212-54105-2.

Levy-Leboyer, Claude. 2003. Gestión de las Competencias. Cómo Analizarlas, Cómo Evaluarlas, Cómo Desarrollarlas (Management of Competencies. How to Analyze, Assess, and Develop Them). Barcelona: Edición Gestión 2000. ISBN 978-8-480-889339.

Liew, Angela, and David Sundaram. 2005. Complex Decision Making Processes: Their Modelling and Support. Paper presented at 38th Hawaii International Conference on System Sciences, Kauai, HI, USA, January 3-6; Washington: IEEE Computer Society, Volume 9. ISBN 0-7695-2268-8-9

Lipshitz, Raanan, Micha Popper, and Victor J. Friedman. 2002. A multifacet model of organizational learning. Journal of Applied Behavior Science 38: 78-98. [CrossRef]

Ljungquist, Urban. 2007. Core competency beyond identification: Presentation of a model. Management Decision 45: 393-402. [CrossRef]

Lopes, Ana P., Kumiko O. Kissimoto, Mário S. Salerno, Fernando J. B. Laurindo, and Marly C. Carvalho. 2012. Innovation Management: A Literature Review about the Evolution and the Different Innovation Models. Paper presented at XVII International Conference on Industrial Engineering and Operations Management, Guimarães, Portugal, July 9-11.

Lundvall, Ben-Åke. 1988. Innovation as an interactive process: From user-producer interaction to the National Innovation Systems. In Dosi, Giovani, Freeman, Christopher, Nelson, Richard, Silverberg, Gerald, and Soete, Luc. 1988. In Technology and Economic Theory. London: Pinter Publishers. ISBN 978-0861879496.

Maassen, Peter A. M., and Johan P. Olsen. 2007. University Dynamics and European Integration. Dordrecht: Springer. ISBN 978-1-4020-5970-4.

Machado, Carolina, and J. Paulo Davim. 2015. Innovation Management: In Research and Industry. Berlin: Walter de Gruyter GmbH. ISBN 978-3-11-035872-8.

Mäkimattila, Martti, Timo Junell, and Tero Rantala. 2015. Developing collaboration structures for university-industry interaction and innovations. European Journal of Innovation Management 18: 451-70. [CrossRef]

March, James G., and Herbert A. Simon. 1958. Organizations. New York: John Wiley. ISBN 063118631X.

Martín-Rubio, Irene, and Diego Andina. 2016. University Knowledge Transfer Offices and Social Responsibility. Administrative Science 6: 20. [CrossRef]

McCoy, Janetta M. 2005. Linking the Physical Work Environment to Creative Context. The Journal of Creative Behaviour 39: 167-89. [CrossRef]

McDermott, R. 1998. Why information technology inspired but cannot deliver knowledge management. California Management Review 41: 103-17.

Moultrie, James, John Clarkson, and David Probert. 2007. Development of a Design Audit Tool for SMEs. The Journal of Product Innovation Management 24: 335-368. [CrossRef]

Murray, Alan, Keith Skene, and Kathryn Haynes. 2017. The Circular Economy: An interdisciplinary exploration of the concept and applications in a global context. Journal of Business Ethics 140: 369-80. [CrossRef]

Mytelka, Lynn K., and Keith Smith. 2002. Policy learning and innovation theory: An interactive and co-evolving process. Research Policy 31: 1467-79. [CrossRef] 
Nielsen, Janni, Leif Bloch Rasmussen, Suzanne Yaganeh, Hernan Bacarini, and Antonio Arciénaga. 2012. Cooperative Innovation Landscapes-Visualising Empirical Findings from an Euro-Latin American Project. Paper presented at Participatory Innovation Conference 2012, Melbourne, Australia, January 12-14.

OECD. 2008. Innovate to Learn, Learning to Innovate. Paris: OECD. ISBN 9789264047976.

OECD. 2017. The OECD Handbook for Innovative Learning Environments. Paris: OECD Publishing.

Owen, Richard, and Nicola Goldberg. 2010. Responsible Innovation: A Pilot Study with the U.K. Engineering and Physical Sciences Research Council. Risk Analysis 30: 1699-707. [CrossRef] [PubMed]

Owen, Richard, David Baxter, Trevor Maynard, and Michael Depledge. 2009. Beyond Regulation: Risk Pricing and Responsible Innovation. Environmental Science Technology 43: 6902-6. [CrossRef] [PubMed]

Perrenoud, Philippe. 2007. Diez Nuevas Competencias para Enseñar. 5ta Edición (Ten New Competencies for Teaching); Barcelona: Editorial Graó. ISBN 978-8-478-273218.

Peteraf, Margaret A., and Mark E. Bergen. 2003. Scanning dynamic competitive landscapes: A market-based and resource-based framework. Strategic Management Journal 24: 1027-41. [CrossRef]

Pighin, Maurizio, and Anna Marzona. 2011. Unlearning/Relearning in Processes of Business Information Systems Innovation. Journal of Information and Organizational Science 35: 59-72.

Poole, Marshall Scott, and Andrew H. Van de Ven. 2004. Handbook of Organizational Change and Innovation. New York: Oxford University Press. ISBN 0-19-513500-8.

Poole, Marshall Scott, Andrew H. Van de Ven, Kevin Dooley, and Michael E. Holmes. 2000. Organizational Change and Innovation Processes: Theory and Methods for Research. New York: Oxford University Press. ISBN 978-0195131987.

Porter, Michael. 1996. What is Strategy? Harvard Business Review 1996: 61-78.

Raffa, Mario, and Giuseppe Zollo. 1994. Sources of innovation and professionals in small innovative firms. International Journal of Technology Management 9: 481-96. [CrossRef]

Rutherford-Silvers, Julia. 2008. The risk management process, tools, and techniques. Included in Rutherford-Silvers, Julia. 2008. In Risk Management for Meetings and Events. A Volume in Events Management. Boston: Elsevier Ltd., Chapter 2; pp. 24-52. ISBN 978-0-7506-8057-8.

Sábato, Jorge, and Natalio Botana. 1968. La Ciencia y la Tecnología en el Desarrollo Futuro de América Latina (Science and Technology in the Future Development of Latin America). Revista de la Integración 1: 15-36.

Sallán, José M., Albert Suñé, Vicenç Fernández, and Joan B. Fonollosa. 2005. Métodos Cuantitativos de Organización Industrial (Quantitative Methods of Industrial Organization), 2nd ed. Barcelona: Universidad Politécnica de Cataluña. ISBN 84-8301-594-3.

Santos Silva, Luan Carlos, Silvia Gaia, Carla Schwengber ten Caten, and Renata Tilemann Facó. 2013. Technology Transfer and Innovation Management: The Brazilian TTOs Challenges. International Journal of Knowledge Management 13: 78-87. [CrossRef]

Savin-Baden, Maggi. 2000. Problem-Based Learning in Higher Education: Untold Stories. Buckingham: SRHE and Open University Press. ISBN 0-335-20338-8.

Schroeder, Roger, Andrew Van de Ven, Gary Scudder, and Douglas Polley. 1986. Managing Innovation and Change Processes: Findings from the Minnesota Innovation Research Program. Agribusiness 2: 501-21. [CrossRef]

Schumpeter, Joseph. ([1939] 2017); Business Cycles: A Theoretical, Historical, and Statistical Analysis of the Capitalist Process. New York: McGraw Hill.

Sengupta, Atri, D. N. Venkatesh, and Arun K. Sinha. 2013. Developing performance linked competency model: A tool for competitive advantage. International Journal of Organizational Analysis 21: 504-27. [CrossRef]

Shane, Scott. 2008. Handbook of Technology \& Innovation Management. New York: Wiley \& Sons. ISBN 978-1-4051-2791-2.

Striukova, Ludmila, and Thierry Rayna. 2015. University-industry knowledge exchange: An exploratory study of Open Innovation in UK universities. European Journal of Innovation Management 18: 471-92. [CrossRef]

Sutz, Judith. 2000. The University-Industry-Government Relations in Latin America. Research Policy 29: $279-90$. [CrossRef]

Sweeney, Linda Booth, and John D. Sterman. 2000. Bathtub dynamics: Initial results of a systems thinking inventory. System Dynamics Review 16: 249-86. [CrossRef]

Thomke, Stefan, and Erick Von Hippel. 2002. Customers as Innovators. A New Way to Create Value. Harvard Business Review 80: 74-81. 
Tidd, Joe. 2001. Innovation Management in Context: Environment, Organization and Performance. International Journal of Management Reviews 3: 169-83. [CrossRef]

Tidd, Joe, John Bessant, and Keith Pavitt. 2005. Managing Innovation: Integrating Technological, Market and Organizational Change. West Sussex: John Wiley \& Sons. ISBN 0-470-09326-9.

Van de Ven, Andrew H. 1986. Progress Report on the Minnesota Innovation Research Program. Strategic Management Research Center-University of Minnesota. Discussion Paper \#51. Available online: http:/ / www.dtic.mil/dtic/tr/fulltext/u2/a167854.pdf (accessed on 18 November 2016).

Van de Ven, Andrew H., and Marshall Scott Poole. 1990. Methods for Studying Innovation Development in the Minnesota Innovation Research Program. Organization Science 1: 313-35. [CrossRef]

Van de Ven, Andrew, Harold Angle, and Marshall Scott Poole. 2000. Research on the Management of Innovation: The Minnesota Studies. New York: Oxford University Press. ISBN 0-19-513976-3.

Van Gils, Maarten J. G. M., and Floris P. J. T. Rutjes. 2017. Accelerating chemical start-ups in ecosystems: The need for biotopes. European Journal of Innovation Management 20: 135-52. [CrossRef]

Veugelers, Reinhilde, and Bruno Cassiman. 2005. R\&D cooperation between firms and universities. Some empirical evidence from Belgian manufacturing. International Journal of Industrial Organization 23: 355-79. [CrossRef]

Von Hippel, Erick. 1987. Cooperation between Rivals: Informal Know-how Trading. Research Policy 16: 291-302. [CrossRef]

Von Hippel, Erick. 1988. The Sources of Innovation. Nueva York: Oxford University Press. ISBN 978-0195094220.

Wenger, Etienne, Richard McDermott, and William Snyder. 2002. Cultivating Communities of Practice: A Guide to Managing Knowledge. Boston: Harvard Business School Press. ISBN 1-57851-330-8.

Wessner, Charles. 2008. An Assessment of the SBIR Program. Washington: National Academy Press. ISBN 978-0-309-11086-0.

White, Margaret, and Garry Bruton. 2011. The Management of Technology and Innovation: A Strategic Approach. Mason: Cengage Learning. ISBN 978-0538478229.

Wollmann, Dewey, and Maria Teresinha Arns Steiner. 2017. The Strategic Decision-Making as a Complex Adaptive System: A Conceptual Scientific Model. Hindawi Complexity 2017: 7954289. [CrossRef]

Wurdinger, Scott D., and Julie A. Carlson. 2010. Teaching for Experiential Learning: Five Approaches That Work. Lanham: Rowman \& Littlefield Education. ISBN 9781607093688.

Yang, Bai-Chuan, Bing-Eng Wu, Pei-Gi Shu, and Ming-Hsien Yang. 2006. On establishing the core competency identifying Model: A value-activity and process oriented approach. Industrial Management $\mathcal{E}$ Data Systems 106: 60-80. [CrossRef]

Yang, Ching-Chow. 2015. The integrated model of core competence and core capability. Journal Total Quality Management \& Business Excellence 26: 173-189.

Zhao, Yingxin, Yanqiu Lu, and Xiangyang Wang. 2013. Organizational unlearning and organizational relearning: A dynamic process of knowledge management. Journal of Knowledge Management 17: 902-12. [CrossRef]

(C) 2018 by the authors. Licensee MDPI, Basel, Switzerland. This article is an open access article distributed under the terms and conditions of the Creative Commons Attribution (CC BY) license (http://creativecommons.org/licenses/by/4.0/). 